\title{
Effects of the Reynolds Number and the Tip Losses on the Optimal Aspect Ratio of Straight-Bladed Vertical Axis Wind Turbines
}

\author{
Stefania Zanforlin*, Stefano Deluca \\ Department of Energy, Systems, Territory and Constructions Engineering \\ University of Pisa, l.go L. Lazzarino, 56122 Pisa, Italy \\ *corresponding author, phone: +390502217145; e-mail: s.zanforlin@ing.unipi.it
}

\begin{abstract}
Aspect Ratio $(A R)$ is one of the main design parameters of straight-bladed vertical axis turbines. This paper will examine whether a high AR, with long blades and low tip losses, or a low AR, with a higher diameter and higher losses, is more suitable to achieve the maximum power output given a fixed cross-sectional area. Traditional Double-Multiple Stream-Tube (DMST) approaches are limited by a lack of tip loss formulations specifically conceived for vertical axis turbines. Therefore, a CFD-3D investigation covering a power range from micro-generation to MW has been done. Results show that both Reynolds number and tip losses strongly influence the aerodynamic performance of the rotor. More advantages seem to be achieved by limiting tip losses rather than increasing chord-based Reynolds number $\left(\mathrm{Re}_{\mathrm{c}}\right)$, addressing towards high $\mathrm{AR}$ at least for medium and large-size turbines. However, as turbine size and wind speed decrease, this difference narrows considerably. For micro turbines, tip losses are balanced by the effects of $R e_{c}$, thus a variation of $A R$ does not imply a variation of $C_{P}$. For all the cases that have been analysed, turbine size and therefore $R e_{c}$ does not appreciably affect the normalized $C_{P}$ distribution along the blade, which only depends on $A R$.
\end{abstract}

Keywords: vertical axis turbine; tip losses; aspect ratio; Reynolds; CFD-3D

\section{Nomenclature}

\begin{tabular}{|c|c|c|c|}
\hline \multicolumn{4}{|c|}{ Latin symbols } \\
\hline$A$ & Turbine cross-sectional area $\left[\mathrm{m}^{2}\right]$ & $\operatorname{Re}_{c}$ & Chord-based Reynolds Number [-] \\
\hline$A R$ & Diameter-based aspect ratio [-] & $T$ & Turbine torque $[\mathrm{N} \mathrm{m}]$ \\
\hline$A R^{*}$ & Chord-based aspect ratio & $T S R$ & Tip-speed ratio [-] \\
\hline$c$ & Blade chord [m] & $V_{\infty}$ & Undisturbed wind speed magnitude $[\mathrm{m} / \mathrm{s}]$ \\
\hline$C_{P}$ & Power coefficient [-] & $y+$ & Dimensionless wall distance [-] \\
\hline$D$ & Turbine diameter $[\mathrm{m}]$ & & \\
\hline$h$ & Local blade height [m] & \multicolumn{2}{|c|}{ Greek symbols } \\
\hline$H$ & Total blade height [m] & $\mu$ & Non-dimensional span-wise position [-] \\
\hline$k$ & Turbulent kinetic energy $\left[\mathrm{m}^{2} / \mathrm{s}^{2}\right]$ & $\vartheta$ & Azimuthal angle [deg] \\
\hline$K$ & Normalized local power coefficient [-] & $v$ & Air kinematic viscosity $\left[\mathrm{m}^{2} / \mathrm{s}\right]$ \\
\hline$N$ & Number of blades [-] & $\rho$ & Air density $\left[\mathrm{kg} / \mathrm{m}^{3}\right]$ \\
\hline$p$ & Static pressure $[\mathrm{Pa}]$ & $\sigma$ & Blade solidity [-] \\
\hline$P$ & Turbine power [W] & $\Omega$ & Turbine revolution speed [rad/s] \\
\hline$R$ & Turbine radius $[\mathrm{m}]$ & $\omega$ & Specific turbulence dissipation rate $[1 / \mathrm{s}]$ \\
\hline
\end{tabular}




\section{Introduction}

It is estimated that within the next 2-3 decades Vertical Axis Wind Turbines (VAWTs) could dominate the wind-energy technology [1]. VAWTs have proved to be more suitable than Horizontal Axis Wind Turbines (HAWTs) for small-scale urban applications thanks to their low noise and vibrations [2], their ability to work with turbulent and skewed flows [3-7] and their lack of need for any active yaw device. Moreover, VAWTs are gaining growing interest for large-scale offshore floating applications because of their higher stability that can help reduce platform costs $[8,9]$. However, VAWTs are penalized by self-starting issues and low efficiency compared to HAWTs even though this disadvantage could be compensated by a higher packing factor in farms due to a much quicker wake dissipation [9]. A further increase in energy production is obtained by placing pairs of counter-rotating VAWTs in close proximity. Such arrangement is experimentally shown to have a beneficial effect on the performance of each turbine $[10,11]$. The physical mechanisms that determine an increase in performance of a turbine pair compared to an isolated one are justified by means of CFD in Ref. [12] and occur in both wind [13] and tidal [14] farms. Similar mechanisms are also observed to significantly increase the power output of ducted small VAWTs for micro generation in urban environments $[15,16]$.

The simplest way to design the 2D characteristics of a conventional VAWT (airfoil shape, solidity, number of blades, optimal tip speed ratio) is the Blade-Element Momentum (BEM) approach that consists in adopting a simplified aerodynamic analysis of the flow near the blade and solving momentum-balance equations across the single, multiple, or double-multiple stream-tube (DMST) passing through the turbine [17]. However, rotor Aspect Ratio $(A R)$, defined as follows, is often set empirically based on the designer's experience since, in order to predict the optimal $A R$ with BEM, blade tip losses need to be modelled according to experimental or CFD-3D investigations.

$$
A R=\frac{H}{D}
$$

Unfortunately, it is not convenient to employ wind tunnels with very different turbine ARs because of geometrical limitations and blockage effects that are difficult to model with an acceptable margin of uncertainty. Although some CFD studies that focus on 3D fluid dynamic losses and, in particular, on blade tip losses [18-26] can be found in literature, they are currently few and not exhaustive since they usually consider a fixed rotor geometry working in a limited number of operating conditions. Wider analyses are not carried out because of the long computation times needed. The effects of Reynolds number on the performance of horizontal axis turbines are well known [27-29]. Numerical investigations carried out for VAWTs by means of DMST models have shown that a parameter that plays a crucial role in defining the best $A R$ is the local or chord-based Reynolds number $\left(\operatorname{Re}_{c}\right)$ [30-32].

$$
R e_{c}=\frac{c R \Omega}{v}
$$

Reynolds number strongly influences the power coefficient of VAWTs since, as $R e_{c}$ increases, the lift coefficient rises as well and the drag coefficient decreases [30, 31]. Therefore, if the turbine cross-sectional area is fixed (to keep the achievable power fixed), it might seem preferable to choose a small AR as it allows higher $R e_{c}$ (indeed an increase in turbine radius leads to an increase in chord and therefore $R e_{c}$ ) [30]. On the other hand, this also implies a short blade length and therefore a growth in tip losses. In some DMST investigations tip losses are completely disregarded whereas, in most of the works, corrections conceived for 
HAWTs [33], generally based upon the Prandtl function [34], are commonly used neglecting the peculiar effects of $A R$ on tip losses of VAWTs.

What would happen if tip losses were correctly accounted for? What are the combined effects of $R e_{c}$ and tip losses for different turbine sizes? To try to answer these questions a comprehensive investigation of the fluid dynamic mechanisms that determine the aerodynamic performance of Darrieus straight-bladed turbines is carried out by means of 3D URANS simulations. In the current paper a simplified two-bladed (H-rotor) turbine with a fixed solidity suitable for medium-size applications is considered. The analysis covers a wide range of aspect ratios $(0.25 \leq A R \leq 3)$ and Reynolds numbers $\left(1.2^{*} 10^{5} \leq R e_{c} \leq 1.6^{*} 10^{7}\right)$. The power coefficient $\left(C_{P}\right)$ is evaluated as follows.

$$
C_{P}=\frac{P}{\frac{1}{2} \rho A V_{\infty}^{3}}=\frac{P}{\frac{1}{2} \rho(H D) V_{\infty}^{3}}
$$

It is calculated with a different cross-sectional area for each case so that turbine sizes from micro generation to $\sim 1 \mathrm{MW}$ can be analysed. Our aim is to provide results that could improve tip loss corrections formulations in order to make DMST models more reliable and effective.

\section{Model set-up and validation}

In this section the set-up of the CFD model is specified. The validation tasks concerning the sensitivity of the results to the mesh density and revolutions number is carried out for the 2-bladed turbine described in section 3.1 and 3.2, whereas the validation of the overall model is done against a small 3-bladed water turbine for which experimental data are available in literature.

\subsection{Turbulence model and discretization schemes}

Turbulence is modeled by means of the k- $\omega$ SST (Shear Stress Transport) model that is widely used in the simulation of VAWTs [18, 21, 35, 36]. The k- $₫$ model of Menter [37, 38] has proved to be well suitable for flows with strong adverse pressure gradients and back-flow, as those occurring in VAWTs, especially when operating at low Tip Speed Ratio (TSR). Tip speed ratio (TSR) is defined as:

$$
T S R=\frac{\Omega R}{V_{\infty}}
$$

The SST formulation is a variant of the standard k- $₫$ model that combines the original Wilcox k- $₫$ model [39], used near the walls, and the standard k- $\varepsilon$ model, employed away from the walls, using a blending function. Moreover, it accounts for the transport of the turbulence shear stress in the definition of the turbulent viscosity. The SST formulation switches to a k- $\varepsilon$ behavior in the free-stream avoiding the problem of the excessive k- $₫$ model sensitivity to the inlet free-stream turbulence properties [44]."

The wall distance from the first layer of cells should be set to keep the dimensionless wall distance $(y+)$ low enough to capture flow separation phenomena. Depending on the boundary layer analysis settings, the suggested values are [40]: $30<y+<300$ for wall functions based simulations, when the mesh is only fine enough to resolve up to the turbulent region, and $1<y+<5$ for fine enough meshes to resolve the laminar sublayer. It must be observed that $y+$ depends on TSR and, for a fixed TSR, it varies during the revolution. We 
set the height of the first cell at the blade surface to guarantee a $y+$ lower than 5 throughout the revolution for all the geometries and the operating conditions of this study. The $y+$ values will be specified in section 3 .

The CFD software used is ANSYS Fluent v15 with the SIMPLE (Semi-Implicit Method for PressureLinked Equations) velocity-pressure coupling algorithm. The spatial discretization is set to Green-Gauss nodebased for gradient. Second order schemes are used for pressure, momentum, turbulent kinetic energy $(k)$ and specific dissipation rate $(\omega)$ formulations. Second order implicit scheme is also adopted for the temporal discretization. Absolute convergence criteria are set to $5^{*} 10^{-5}$ for the residuals of each variable (continuity, velocity components, turbulence kinetic energy and specific dissipation rate). Time-step has been chosen according to the observations of Balduzzi et al. [41]. They note that, in most of VAWTs CFD simulations, it corresponds to the lapse of time in which the rotor makes a rotation between $0.5^{\circ}$ and $2^{\circ}$. Moreover, they perform a sensitivity analysis using angular time-steps between $0.135^{\circ}$ and $0.405^{\circ}$ finding relevant differences only for very low TSRs. As done by Raciti Castelli et al. [18], Orlandi et al. [7] and Delafin et al. [42], we set an angular time-step of $1^{\circ}$ rotation for all the simulations of this paper. Our choice also agrees with the time dependence study of Elkhoury et al. [42], who found extremely close results by setting time-steps of $1.2^{\circ}$ and $0.6^{\circ}$ and such choice only slightly differs from the indications by Marsh et al. [21], who determined that the result independence is achieved for a time-step of $0.9^{\circ}$.

\subsection{Mesh analysis}

Mesh creation is one of the most critical issues in CFD simulations. High-quality meshes enhance the robustness of convergence, the efficiency of calculations and the accuracy of the solution [23]. For this paper, structured multi-block grids have been generated throughout the computational domain and an extensive use of the "O-grid" technique was made, where all the single blocks are still structured (i.e., only made by hexahedral cells). The technique improves grid quality and allows a higher concentration of cells only in those regions that require high resolution (for instance, the zone around blade tips) and avoids that any local distribution refinement extends to the other two dimensions throughout the grid volume, thus limiting the total cell number.

To simulate the turbine rotation two different grids are used: a fixed sub-grid with the external dimensions of the flow domain and a rotating sub-grid that includes the VAWT geometry. The latter possesses a relative motion with respect to the former grid by means of the sliding mesh technique. Fig. 1-a shows the domeshaped rotating grid on a horizontal plane normal to the rotor axis. As can be seen in the top-right pane of Fig. $1-\mathrm{a}$, the mesh is progressively refined within an elliptical region around the blade by adopting an exponential law with the aim to resolve the separated flow regions at high angle of attack. Fig. 1-b illustrates the grid on a vertical plane passing through the leading and the trailing edges of a blade for a geometry characterized by $A R=1.9$. An exponential node distribution along the blade span is adopted (Fig. 1-d) so that a higher resolution of the grid can be achieved from the blade tip to about one and half chords away from it in the span-wise direction. This allows flow details and tip vortices generation to be accurately described. Coloured ribbons in Fig. 1-c and Fig. 1-d indicate the cell layers where local torque is recorded during simulations. These values are needed to compute the local power coefficient $C_{P}(\mu)$, that is the power coefficient evaluated on the ribbons' infinitesimal cross-sectional area $\Delta h^{*} D$ for different positions on the blade span, expressed by $\mu$ ( $\mu=0$ is located at the midspan). All the above-mentioned coefficients as well as the normalized local power coefficient $(K)$ are defined as follows. 


$$
\begin{gathered}
\mu=\frac{h}{0.5 H} \\
C_{p}(\mu)=\frac{T(\mu) \Omega}{\frac{1}{2} \rho(\Delta h D) V_{\infty}^{3}} \\
K=\frac{C_{p}(\mu)}{C_{p}(0)}
\end{gathered}
$$

164

165

166

167

168

169

170

171

172

173

174

175

176

177

178

179

180

181

182

183

184

185

186

187

188

189

190

191

192

193

194

195

196

197

198

199

In order to test the code sensitivity to the grid cells number, four mesh resolutions were tested for the rotor sub-grid while the fixed sub-grid remained substantially the same (with minimum corrections in order to avoid important differences in the dimensions of the cells on the domains' interface). Comparisons among the meshes were made for $A R=0.8$. Cells number and distributions are resumed in Tab.1.

The "medium" grid is characterized by 220 cells along the airfoil perimeter (110 on each side of the airfoil) and 68 cells along the semi-span direction. To obtain the "fine" grid, cell number has been increased by $30 \%$ along the airfoil perimeter and by $40 \%$ along the semi-span direction. Moreover, the height of the first cell layer at the tip has been shortened. The "coarse_1" grid is obtained from the "medium" grid by halving the cell number along the semi-span direction, while the "coarse_2" grid is obtained by reducing by $15 \%$ and $35 \%$ the number of cells along the semi-span direction and the airfoil perimeter respectively and by increasing the height of the first layer at the tip. Fig. 2-a depicts a schematic representation of the upwind and downwind paths of the blade in one revolution. Fig. 2-b and Fig. 2-c show the grid sensitivity results in terms of the instantaneous one-blade power coefficient $\mathrm{C}_{\mathrm{P}}(\vartheta)$ and the local $\mathrm{C}_{\mathrm{P}}(\mu)$.

It can be seen that the parameter playing the most important role is the cell number along the airfoil perimeter whereas a rather small cell number along the blade span ( 34 cells on half blade) could be sufficient, provided that an exponential distribution capable of capturing fluid-dynamic phenomena at the tips of the blades is chosen. However, a cell distribution corresponding to the "medium" grid was prudently chosen for all the simulations of the current study.

\subsection{Solution convergence}

Simulations have been performed to determine the minimum number of revolutions required to obtain a converged solution. A solution is deemed converged when the value of $C_{P}$, averaged on the last revolution, shows a deviation of less than $1 \%$ compared with the value obtained for the previous revolution. As shown in Fig. 3-b, this happens after only 4 revolutions for the lowest $A R$, that is 0.25 . However, the convergence becomes slower and slower as $\mathrm{AR}$ grows, requiring at least 11 revolutions for the highest $A R$, that is 3 . Fig. $3-$ c shows the influence of the revolution number on $\mathrm{K}$ for $A R=0.8$ confirming that a certain number of revolutions (in this case 8) can concurrently satisfy both the turbine averaged $C_{P}$ and the spanwise local $C_{P}$ convergences. According to the results of Fig. 3, we chose to simulate 6, 7, 8, 10 and 11 revs. for $A R$ of 0.25 , $0.5,0.8,1.9$ and 3 respectively.

\subsection{Overall validation of the model}

The validation of the overall computational model has been done against experimental data available in literature for a small 3 straight-bladed Darrieus water turbine tested by Maître et al. [44] in a hydrodynamic tunnel. The diameter $(D)$ and blade length $(H)$ are both $175 \mathrm{~mm}$, therefore $A R$ is 1 . The hydrofoil shape is a 
modified version of NACA0018 obtained by warping the profile from mid-chord so that the camber line fits the circular blade path. Chord length is $32 \mathrm{~mm}$, thus the solidity $(\sigma)$ defined as:

$$
\sigma=\frac{N c}{2 \pi R}
$$

is $17.5 \%$, that is in the range typically adopted for hydrokinetic turbines. Details of geometry and operating conditions can be found in our previous paper [13], together with reports of a series of 2D simulations. The validation step of the current study examines 3D simulations based on high-quality structured multi-blocks meshes. The domain cross section corresponds to that of the experimental test-cell. A longer upstream domain is chosen to allow a non-uniform and realistic velocity profile to be developed since the only known datum is the mean flow speed based on the pump flow rate. The downstream domain length is set to allow a full development of the wake so as to avoid numerical problems on the outlet boundary. As done by Ferreira for wind tunnel tests [43], inlet and outlet are placed 10D upwind and 14D downwind with respect to the rotor. Since water speed is $1.75 \mathrm{~m} / \mathrm{s}$ at $T S R=2$ (that is the optimal TSR) the turbine works with a $R e_{c}$ of 179000 . Maître et al. [42] evaluated the influence of $\mathrm{y}+$ on results finding that averaged $\mathrm{y}+>1$ leads to an overestimation of pressure drag in turbines subjected to significant flow separation as typically occurs for high solidity water turbines. For this reason cell distributions all around the blades are fine enough to achieve $y+\ll 1$. In particular, for TSR $=2$, the averaged $\mathrm{y}+$ was 0.19 in our previous $2 \mathrm{D}$ simulations and is 0.40 in the current 3D simulations. Fig. 4 shows a comparison between $C_{P}(T S R)$ curves from the current CFD-3D analysis, experimental tests and CFD-2D by ref. [42], and our previous CFD-2D [13]. The high values of experimental and numerical $\mathrm{C}_{\mathrm{P}}$ can be justified by the high blockage ratio (frontal turbine area / test-section area $=0.35$ ) that increases the speed of the flow approaching the turbine. CFD-3D simulations allow the description of important effects such as vertical blockage, due to the water tunnel's, walls and tip losses making the numerical results fairly close to the experimental ones. Despite the trend shape and the optimal TSR are matched for all the curves in Fig. 4, it can be noticed that CFD-2D performance appears generally very high. For instance, for $\mathrm{TSR}=2, \mathrm{C}_{\mathrm{P}}$ from our $2 \mathrm{D}$ and $3 \mathrm{D}$ analyses are 0.543 and 0.356 respectively. This means that CFD-3D performance is cut by $34.4 \%$ with respect to the CFD-2D performance. It is necessary to underline that the 2D domain does not include the turbine shaft but the 3D one does, so hydrodynamic losses due to the shaft are taken into account. However, shaft losses are expected to be very small in comparison with blade tip losses and therefore only the latter are considered responsible for the gap that has been found between 2D and 3D performance. The high value of tip losses can be explained considering that the turbine is characterised by a chord-based aspect ratio, defined as $A R^{*}=H / c$, of 5.47, which is a rather low value and therefore compatible with significant tip losses. At the end of section 4.4 it will be shown that this percentage gap between $2 \mathrm{D}$ and $3 \mathrm{D}$ is aligned with the main outcomes of this study.

\section{Turbine geometry and domain assumptions}

The turbine blades, whose profile is NACA0015, are connected to the struts at $0.25 c$ from the leading edge. Blade solidity $(\sigma)$ is $4.8 \%$. The number of blades (two instead of the more commonly used three) is chosen in order to contain the grid cell number and therefore computational time. For the same reason, turbine shaft, ring and struts usually adopted to fix and support the blades at its position have been neglected since the overall cell number in structured multi-bloks grids greatly depends on geometrical details. Moreover, for $A R$ $\geq 0.8$, only half domain is considered (therefore, a symmetry plane passing for the half of the blade's length is assumed). 
To prevent that lateral and vertical blockage effects or inlet domain length lead to an overestimation of $C_{P}$ due to an increase in velocity magnitude of the approaching flow, the dimensions of the external fixed domain are much larger than the minimum ones recommended in literature [46]. Domain crosswise width, vertical width and inlet length are prudently set to $60 \mathrm{D}, 40 \mathrm{H}$ and $34 \mathrm{D}$ respectively. The downstream length is $32 D$.

In order to contain grid generation time, only six set of meshes have been generated, one for each $A R$ analysed. This implies that the analysis of different turbines characterised by the same $A R$ is done by scaling the same set of rotating and fixed grids. As reported in Tab. 2, grid size ranges from $3.58 * 10^{6}$ cells to $6.74 * 10^{6}$ cells, depending on $A R$ and domain completeness (half or total), with most of them ( 72\%) belonging to the rotating domain. Keeping the same grid sets implies the variation of the averaged $y+$, which results $<5.0,<$ $2.0,<0.9$ and $<0.3$ for a turbine cross-area of 2000, 625, 52 and $4 \mathrm{~m}^{2}$ respectively. Therefore, only for the two smallest cross-areas the height of the first cell layer was within the viscous sub-layer ensuring accurate results [21]. This happens because grid scaling entails a linear variation of the chord and of the height of the first cell layer as well. It can be easily proved (by combining the definitions of $y+$ and skin friction coefficient) that $y+$ of those cells grows less-than-linearly with the chord. Considering that some authors noted that $y+$ greater than 1 leads to an overestimation of the pressure drag in case of deep flow separation [42], some of our values could appear too high. However, the adopted TSR guarantees attached flow for the turbine sizes of $2000 \mathrm{~m}^{2}$ and 625 $\mathrm{m}^{2}$ while for those cases in which some separation has been observed (smallest turbines, see paragraph 4.3) $y+$ is satisfying low.

260

261

262

263

264

265

266

267

268

269

270

271

272

273

274

275

\section{Results}

To the author's knowledge this is the first systematic 3D CFD study that has been published on VAWT aerodynamic performance on a relatively wide range of ARs and power sizes. The simulations required six months to run on $4 \mathrm{PCs}$ with a total CPU cores count of 42 , each with a maximum frequency of $3.40 \mathrm{GHz}$.

Firstly, we take a qualitative look on some phenomenological evidences about tip vortex formation and its consequences. Then, we show the quantitative effects of $A R$ on tip losses and turbine performance while keeping $R e_{c}$ fixed. Afterwards, the focus is moved on the combined effects of $R e_{c}$ and tip losses in determining the optimal $A R$ that allows the maximum power output, keeping TSR fixed. The effect of TSR on both the global turbine performance and the local performance distributions along the blade span is analysed for the smallest turbine size taken into consideration at a wind speed typical of urban environments. Finally, tip losses are globally quantified in terms of blade length virtual shortening and loss of material with respect to the ideal case of infinite blade and to the optimal $A R$.

\subsection{Effects of Aspect Ratio at fixed turbine diameter}

For this first investigation turbine diameter is fixed $(D=50 \mathrm{~m})$ and representative of high power applications and thus high $R e_{c}$. A wind speed of $10 \mathrm{~m} / \mathrm{s}$ is assumed. TSR is 3.5, which is slightly higher than the optimal TSR found for this diameter by means of preliminary CFD-2D simulations. The aim is to assess the effects of $A R$ on turbine performance when $\operatorname{Re}_{c}$ (that only depends on $D$ and blade speed) is fixed. Five different $A R s$, ranging from 0.25 to 3, have been chosen and are shown in Tab. 3. Even though it would be interesting to simulate higher $A R s$, such task would be prohibitive because of the huge computation times and number of revolutions required (rapidly increasing with $A R$, as already shown in Fig. 3-b) by such huge grid sizes. 
Flow field on the $X Z$ mid-plane for $A R=1.9$ and blade angular position $\vartheta=90^{\circ}$ is illustrated in Fig. 5. Wind is blowing from left; the blade on the left is at halfway of the upwind route while the blade on the right is at halfway of the downwind route. From the velocity magnitude map (Fig. 5-a), it can be noticed that the the highest velocity of the flow approaching the downwind blade is at the blade tip. This happens since the upwind blade is not able to extract power at the tip, as will be discussed later on. The vorticity map shown in Fig. 5-b gives evidence of the occurring of tip vortices. In particular, the evolution of vortices generated at the tip of the upwind blade can be seen. According to the theory of finite wings [45], tip vortices are generated by the pressure difference between the pressure and the suction sides of any finite wing (airplane wing, HAWT and VAWT blade). Near the blade tip, the flow approaching the blade pressure-side is no longer able to follow the blade profile and curls around the tip towards the suction-side. This establishes a circulatory motion that trails downstream of the blade. The vortex generation is also evident in the vertical velocity map (Fig. 5-c), showing an increasing spanwise velocity component of the flow from midspan towards the tip on the blade pressureside and a decreasing spanwise component of the flow from the tip to the midspan on the blade suction-side. This happens on the upwind blade tip but it is also visible, to a lesser extent, on the tip of the downwind blade.

The three-dimensional features of the flow approaching and leaving the blade tip are visible in Fig. 6-a and Fig. 6-b. The flow "leakage" around the tip decreases the pressure difference between the suction and pressure sides, as depicted in Fig. 6-c, thus reducing lift. Moreover, tip vortices imply a localized huge pressure drag increase. As a result, performance drastically drops at the blade tip.

However, the effects of tip vortices are not only confined near the tip but also propagates along the span causing vertical velocity components in the flow approaching the blade. These $\mathrm{z}$-velocities components are maximum at the vortex core, where the vortex strength is the highest, and decrease towards the blade midspan, as the vortex strength gradually weakens. Z-velocity calculated on pressure-surface (positive values) and on suction-surface (negative values) of the blade are shown in Fig. 7-a.

Such peculiar velocity field is shown in Fig. 7-b and Fig. 7-c and justifies a performance drop at the tip. A red line $1 c$ long and located $1 c$ before the blade has been superimposed on the path-lines arriving on the blade (Fig. 7-b) to emphasize that the effective turbine cross-sectional area results lowered. Fig. 7-c depicts the path-lines departing from a segment $1 c$ tall and placed $1 c$ before the blade tip, confirming that most of the flow travelling across that segment climbs over the tip. Moreover, the z-velocity of the incoming flow can also justify the spanwise reduction of the attack angle. In fact, a z-velocity component entails a reduction of the flow axial velocity, as can be seen in Fig. 7-d depicting the specific flow rate across the turbine calculated on the $\mathrm{XZ}$ mid-plane at different $\mu$ positions along the span. (In relation to the sudden flow rate increase visible in Fig. 7-d at the end of the blade, it must be noted that it is due to the flow circulated over the tip during the upwind trajectory, as also recognizable in Fig. 5-a). The x-velocity loss leads to a shortening of the apparent velocity projection on the plane normal to the turbine axis (the only torque-producing component) and to a reduction of the attack angle. As a result, the resulting lift force and consequent torque and power are gradually reduced from midspan to tip as shown by the instantaneous one-blade $C_{P}$ curves (Fig. 8-a) calculated for different positions. As experimentally visualized by Ferreira et al. [48], the power reduction varies with the angular position of the blade and reaches its maximum at the position for which the highest power on the midspan is achieved (a dozen degrees after $90^{\circ}$ for attached flow conditions). Fig. 8-b shows the behaviour of tangential and normal (radial) forces per unit of blade surface vs $\mu$ calculated at $\vartheta=90^{\circ}$. It can be seen that the effects of tip vortices start to be significant at $2 c$ from the tip and cause a rapid drop $1 c$ from the tip. It can be noted that, despite $C_{P}$ becoming negative at the tip, the normal force appears reduced by about one third. 
To complete this qualitative analysis on the origin of tip-vortex losses, Fig. 9 shows the pressure coefficient (that is representative of lift), turbulent kinetic energy, wall shear stress and vorticity (that are representative of drag) calculated at $\vartheta=90^{\circ}$ for different $\mu$. It is interesting to observe that drag spanwise variations do not follow lift variations. Indeed, the effects on lift are well noticeable at $\mu=0.91$ whereas drag remains the same until $\mu \sim 0.97$ and suddenly increases after $\mu=0.98$. In other words, the attack angle reduction determines the spanwise lift distribution but does not affect drag (except for the tip), contrary to the conclusions of the classical downwash approach applied to stationary wings.

Fig. 10-a and Fig. 10-b show the blade performance for different $A R s$ in terms of $C_{P}$ and $K$ along the adimensional semispan $(\mu)$. Two effects can be observed as a consequence of a blade shortening and therefore of a decrease in $A R$ : a $C_{P}$ decrease at the midspan $(\mu=0)$ and a more rapid drop in $C_{P}(\mu)$. All the turbines have the same chord and only differ in blade length, therefore, it is also interesting to compare the spanwise performance distribution vs the absolute blade length (instead of the adimensional length). For this purpose, in Fig. 10-c, the turbines have been "moved" in order to have the same abscissa at the blade tip in order to simplify the performance comparison at a certain distance from the tip. It can be seen that, for more than one chord $(3.77 \mathrm{~m})$ away from the tip, all the blades experience the same poor $C_{P}$. This should not be surprising since the vortex strength (which, for a VAWT, depends on the blade tangential velocity and chord length) is the same. Moreover, the $C_{P}$ distributions appear almost the same proving that tip vortex effects propagate along the spanwise direction in a similar way for all the blade lengths.

\subsection{Combined effects of Reynolds number and Aspect Ratio}

Four turbine cross-sectional areas are considered ranging from microgeneration to $\sim 1 \mathrm{MW}$. For each of them, five ARs are simulated, as summarized in Tab. 4. The simulations are performed for a wind speed of 10 $\mathrm{m} / \mathrm{s}$. TSR is kept at 3.5 for all the turbine cross areas despite the optimal TSR is expected to be slightly different for different $R e_{c}$. This choice is made to avoid changing too many parameters simultaneously and to make the interpretation of the results easier. The reader can find a discussion on the effects of TSR in paragraph 4.3. The question we are going to deal with is: given a certain power size, what is the AR that guarantees the best aerodynamic performance? The role played by two main parameters needs to be analysed: Reynolds number and tip losses.

The beneficial effects of an increase in $R e_{c}$ on the performance of HAWTs and VAWTs are well demonstrated by studies based on 2D numerical approaches [27-32]. If the blades of a VAWT were infinitely long, as assumed in 2D analyses, it would be convenient to adopt a large diameter since it would imply a large chord and therefore high $\operatorname{Re}_{c}$. However, if the power size and therefore the turbine cross-area are fixed, a large diameter would entail short blades (large $A R$ ) and consequently high tip losses caused by tip vortices, as shown in paragraph 2.3. The diagrams of Fig. 11 show the turbine $C_{P}$ for the cases listed in Tab. 4. It can be seen that both $R e_{c}$ and $A R$ strongly influence the aerodynamic performance. However, the growth in performance is more significant for an increase in $A R$ rather than in $R e_{c}$, at least for medium and large-size turbines. In fact, since lift-to-drag ratio is very high for $R e_{c}>1 * 10^{6}$ and is weakly influenced by $R e_{c}$ variations due to different $A R s$, the performance of medium and large turbines is almost entirely affected by tip losses and by how such losses depend on $A R$. Our results agree with Armstrong et al. [49], who observed that the power production of a turbine is independent of Reynolds number if it is sufficiently high. 
However, as turbine size and wind speed decrease $\left(\operatorname{Re}_{\mathrm{c}}<1 * 10^{6}\right)$ and, therefore, drag and flow separation play a more and more important role, $C_{P}$ is increasingly influenced by $R e_{c}$. For micro-generation sizes (crosssectional area of $4.34 \mathrm{~m}^{2}$ in Tab. 4) and $A R \geq 0.8$, a variation of $A R$ does not appreciably affect $C_{P}$. This happens since any favourable effect due to a $R e_{c}$ increase is balanced by a detrimental growth of tip losses and viceversa.

Diagrams in Fig. 12 illustrate the local distribution of both absolute and normalized $C_{P}$ along the semispan vs the normalized blade length $\mu$, explaining how tip losses are related to $A R$. At a fixed turbine cross area, the two effects already found in paragraph 4.1 as a consequence of a blade shortening and therefore of an $A R$ decrease can be observed: a $C_{P}$ decrease at the midspan $(\mu=0)$ and a more rapid $C_{P}(\mu)$ reduction. For $A R=0.25$ (corresponding to a blade-based $A R^{*}$ of just 3.3) a large portion of the blade appears inoperative because of the flow incidence reduction induced by tip vortices. For instance, for $A R=0.25, C_{P}$ is halved (with respect to $C_{P}$ at the semispan) at $\mu=0.83$ whereas for $A R=3$ it is halved at $\mu=0.97$. These results suggest that, for all the power sizes taken into account, $A R<0.8\left(A R^{*}<10.6\right)$ should be avoided.

Finally, we highlight that the effect of $R e_{c}$ on the features of the normalized $C_{P}(\mu)$ curve is negligible (Fig.11-b, d, f, h). This evidence has an important practical consequence since it could simplify the implementation of tip loss corrections to be used in DMST models.

\subsection{Effects of Tip Speed Ratio on the performance of small turbines}

For micro-generation size turbines further simulations have been performed for a wind speed of $5.7 \mathrm{~m} / \mathrm{s}$ that is more representative of urban conditions. Because of flow separation phenomena, the optimum TSR is expected to increase as the turbine size and the wind speed decrease. To verify the effects of TSR on performance three different TSRs have been simulated: 3.5, 3.75 and 4. In order to facilitate the comparison with the other cases of this study, overall $C_{P}$ are reported in Fig. 11, while $C_{P}(\mu)$ and $K(\mu)$ are reported in Fig. 12. Results in Fig. 11 show that TSR greatly affects the turbine performance, and that the optimal TSR varies with $A R$ : it is 3.75 for $A R$ of 1.9 and 3; it is 3.5 for $A R$ of $0.8,0.5$ and 0.25 . In the following we explain why different TSR are needed by analysing the effects of TSR on the local performance for two significant cases: $\mathrm{AR}=3$ and $\mathrm{AR}=0.8$.

To justify the poor performance exhibited by $A R=3$ in case of $T S R=3.5$ and why it is sufficient to increase $T S R$ to 3.75 to obtain an increase of $C_{P}$ from 0.30 to 0.33 we must analyse the performance distribution along the blade semispan. Fig. 13 allows to compare $C_{P}(\mu)$ curves obtained for $A R=3$ with different TSRs. The curve of TSR=3.5 exhibits a "deflation" from the midspan to about $\mu=0.80$ while the best performance is achieved for $\mu$ ranging between 0.85 and 0.92 . We must remember that tip vortices affects $C_{P}(\mu)$ by means of the reduction of the incidence of the flow approaching the blade. This reduction gradually increases going from midspan to the tip, allowing better local performance on the outer part of the blade since it reduces flow separation. Far from the tip, the attack angle reduction is much smaller and then flow separation occurs [19]. Fig. 14 show $C_{P}(\vartheta)$ curves for different $\mu$ for $\mathrm{AR}=3$, TSR=3.5 (Fig. 14-a) and TSR=4 (Fig. 14-b). For TSR=3.5 it can be seen that from midspan to $\mu=0.71$ the angular positions $\vartheta$ corresponding to the maximum $C_{P}(\vartheta)$ appears anticipated with respect to the outer part of the blade. In particular, $C_{P}(\vartheta)$ curves for $\mu=0.10$ and $\mu=0.71$ have their maxima at $\vartheta=89^{\circ}$ and $\vartheta=90^{\circ}$ respectively (whereas in the outer part of the blade the maximum occurs at $94^{\circ}$ ) followed by a sudden drop that indicates stall occurrence. As a result, the only way to avoid flow separation in blades characterized by high $A R$ is to increase $T S R$. For this reason, as far as $\mu=0.90, T S R=3.75$ and $T S R=4$ work better than $T S R=3.5$ as also confirmed by the perfect alignment of the peaks of $C_{P}(\vartheta)$ curves calculated for different $\mu$ for $T S R=4$ (Fig. 14-b). However, an increase in TSR leads to a performance worsening 
on the outer part of the blade due to an excessive reduction of attack angle. Therefore, for $A R=3$ and $A R=1.9$, the best compromise is $T S R=3.75$.

On the other hand, two reasons can explain why the best $T S R$ is 3.5 for $A R=0.8: R e_{c}$ is higher and consequently separation is less likely and the blade is much shorter, so tip vortices effects are significant in reducing attack angle until midspan. As shown in Fig. 15 for all the TSR simulated, $\mathrm{C}_{\mathrm{P}}$ at midspan $(\mu=0)$ for $A R=0.8$ is significantly higher than the one for $A R=3$. This confirms what was observed, to a lesser extent, in Fig. 12 in case of high wind speed: micro-turbines operating at low wind speeds are more sensitive to $R e_{c}$ effects than to tip vortices effects. However, since the longer is the blade, the flatter is the $C_{P}(\mu)$ curve, the blade-averaged $C_{P}$ of $A R=3$ exceeds that of $A R=0.8$ even in case of low wind speed, provided the optimum $T S R$ is adopted $(T S R=3.75)$.

Finally, we observe that for low wind speed the best performance is achieved by AR=1.9 (see Fig. 11). This $A R$ seems to allow a reduction in both flow separation and tip losses phenomena due to high enough values of $R e_{c}$ and $A R$.

\subsection{Tip loss assessment}

As observed by Balduzzi et al. [19], the global effect of tip vortices is a virtual reduction of the effective blade length. Many parameters concur to determine the length of the inoperative portion of the blade such as solidity, number of blades, TSR and AR. In the current analysis, since solidity, blade number and TSR are fixed, the only responsible for a tip loss variation is a change in $A R$ or, coming to the same conclusions, in the chordbased aspect ratio, $A R^{*}$. For completeness' sake, Tab. 3 and 4 also report the corresponding $A R^{*}$ values. In this paragraph, the tip effects analysed in 3.3 are quantified as number of lost chords (considering both tips of the blade) with respect to the performance of an ideal turbine with infinite blade length. Since our 3D grids are much coarser than the 2D grids used to evaluate the optimal TSR, a direct comparison with 2D results could be influenced by grid effects. Therefore, for each case we have considered (each with different cross-sectional area and $A R$ ), we preferred assuming as "infinite-blade turbine" a 3D turbine with the same diameter (and therefore the same $R e_{c}$ ) and blades long enough to allow neglecting tip losses.

In agreement with $\mathrm{Li}$ and Calisal [50], who applied a vortex numerical method to investigate tip losses extension as a function of $A R$ and found out that tip effects are less than $5 \%$ for $A R \geq 6$, we assumed the $C_{P}$ at the midspan of a turbine with $A R=6$ as $2 \mathrm{D}$ performance. Since it would be prohibitive to simulate such high $A R$ by means of CFD-3D, the values have been extrapolated in the following way. Firstly, a fitting curve based on all the simulations carried out for $A R=3$ has been generated in order to obtain $C_{P}$ for $\mu=0$ as a function of $R e_{c}$ and, therefore, of diameter (Fig. 16-a). Secondly, in order to extrapolate a similar function valid for AR=6, we fixed $R_{c}$ corresponding to $\mathrm{D}=50 \mathrm{~m}$ making use of the results of Fig. 10-c to estimate $C_{P}$ at midspan for $\mathrm{AR}=6$ (corresponding to the abscissa zero in the fitting curve of Fig. 16-b). In this way we evaluated the ratio between $C_{P}(\mu=0)$ for $A R=6$ and $A R=3$. Finally, this ratio (equal to 1.023) has been used to scale the fitting curve of Fig. 16-a.

The results of the blade virtual shortening, expressed as number of lost chords, are condensed in Fig. 17a. A continuous increase of the blade virtual shortening occurs as $A R$ increases. This is due to the fact that, despite two blades with different length work with about the same performance at a certain distance from the tip (as seen in Fig. 10-c), longer blades works with a lower $C_{P}$ than the "2D" $C_{P}$ in the remaining part of the blade due to tip effect propagations. The relatively low virtual shortening exhibited by micro-turbines for 0.8 $\leq A R \leq 3$ indicates that the reference " $2 \mathrm{D}$ " $C_{P}$ is low in itself. It should be verified whether the adopted TSR is 
adequate or if it would be better to slightly increase TSR to mitigate flow separation (as found in 4.3). The same results, in terms of percentage of "lost material" with respect to the performance of the corresponding infinite-blade turbine, are shown in Fig. 17-b. All these outputs are also reported in Tab. 4 and, for completeness' sake, in Tab. 3 for a fixed diameter. However, from a practical point of view, it might be more useful to assess the lost material if an $A R$ different from the best one ( $A R=3$, for all the cases described in 4.2) was adopted, as depicted in Fig. 17-c. We highlight that $A R=1.9\left(\mathrm{AR}^{*}=25.2\right)$ implies a relative loss of material of just few percent with respect to $A R=3\left(A R^{*}=39.8\right)$. For larger turbines, for which tip losses are significant, $A R$ should be greater than $1\left(A R^{*}>13.3\right)$ to keep relative material loss below $10 \%$.

We conclude this section showing that the high gap between CFD-3D and CFD-2D performance found in the validation section (2.4) about the small water turbine can be considered consistent with the outcomes reported in Fig. 17-b. First of all, it must be noted a great difference in solidity: $\sigma=4.8 \%$ for the wind turbine, $\sigma=17.5 \%$ for the water turbine. As a consequence, given an $A R$ value (for instance, 1 , that is the $A R$ of the water turbine), the two turbines exhibit different blade-to-chord ratios $\left(A R^{*}\right)$. Since the tip vortex strength increases with the chord length, it is reasonably expected that the higher is $A R^{*}$, the greater are the tip losses in percentage. Therefore, in order to use Fig. 17-b to extrapolate predictions for a different turbine, it could be meaningful to use $A R^{*}$ instead of $A R$. Moreover, from purple curve of graph 16-b with $A R^{*}$ of 5.47 (see Tab. 3 for the conversion $A R$-to- $A R^{*}$ ) a percentage loss of material of $31.7 \%$ can be found. This value is very close to the $3 \mathrm{D}$ losses found in section 2.4 for the water turbine, that is $34.4 \%$ comprising the tip and the shaft losses.

\section{Conclusions}

In the design of VAWTs an important parameter that needs to be assessed in order to maximize the turbine efficiency is the Aspect Ratio $(A R)$. This study shows that CFD-3D can be a useful methodology to investigate the combined effects of blade tip losses and $R e_{c}$ on the performance of VAWTs and, therefore, to find the turbine's optimal $A R$, that gives the best $C_{P}$. The novelty of this study is its systematic character, because it analyses the aerodynamic performance of VAWTs in a relatively wide range of ARs and power sizes, going from micro-generation to MW. The main findings are the following.

Both $R e_{c}$ and tip losses strongly affect $C_{P}$. For all the power sizes taken into account, $A R<0.8\left(A R^{*}<10.6\right)$ should be avoided in order to contain tip losses.

For large and medium size turbines, the effects of tip losses always prevail on the effects of $R e_{c}$. In other words, it is more convenient to adopt longer blades and therefore an $A R$ as high as possible.

As size decreases, the role played by $R e_{c}$ arises. For the smallest size taken into account (microgeneration) the effects of tip losses appear balanced by the effects of $R e_{c}$. This means that, for $A R \leq 0.8$ $\left(A R^{*} \leq 10.6\right)$, a variation of $A R$ does not result in a significant variation of $C_{P}$, especially at low wind speeds typical of urban and sub-urban environments. However, attention should be payed to the choice of TSR since the optimum value changes with $A R$; for high $A R$ a slight increase of TSR mitigates flow separation in the central portion of the blade.

The turbine size, and therefore $R e_{c}$, does not appreciably affect the normalized $C_{P}$ distribution along the blade which, since in the current investigation solidity and TSR are fixed (with the only exception of section 3.4), only depends on $A R\left(A R^{*}\right)$.

This work also show that due to the continuous growing of computing resources available to CFD users, the use of full CFD-3D tools for VAWTs is possible without the need for unrealistic computational resources or time requirements. 


\section{Funding}

This research did not receive any specific grant from funding agencies in the public, commercial, or not-forprofit sectors.

\section{References}

[1] M.R. Islam, S. Mekhilef, R. Saidur, Progress and recent trends of wind energy technology, Renew. Sustain. Energy Rev. 21 (2013) 456-468. doi:10.1016/j.rser.2013.01.007.

[2] S. Tullis, A. Fiedler, K. Mclaren, S. Ziada, Medium-solidity Vertical Axis Wind Turbines for use in Urban Environments, VII World Wind Energy Assoc. Conf. (2008).

[3] F. Toja-Silva, A. Colmenar-Santos, M. Castro-Gil, Urban wind energy exploitation systems: Behaviour under multidirectional flow conditions, Opportunities and challenges, Renew. Sustain. Energy Rev. 24 (2013) 364-378. doi:10.1016/j.rser.2013.03.052.

[4] H. Riegler, HAWT versus VAWT, Refocus. 4 (2003) 44-46. doi:10.1016/S1471-0846(03)00433-5.

[5] S. Mertens, G. van Kuik, G. van Bussel, Performance of an H-Darrieus in the Skewed Flow on a Roof, J. Sol. Energy Eng. 125 (2003) 433. doi:10.1115/1.1629309.

[6] C.S. Ferreira, G.J.W. van Bussel, G. van Kuik, An analytical method to predict the variation in performance of a H-Darrieus in skewed flow and its experimental validation, in: Eur. Wind Energy Conf., 2006.

[7] A. Orlandi, M. Collu, S. Zanforlin, A. Shires, 3D URANS analysis of a vertical axis wind turbine in skewed flows, J. Wind Eng. Ind. Aerodyn. 147 (2015) 77-84. doi:10.1016/j.jweia.2015.09.010.

[8] M. Borg, M. Collu, A comparison between the dynamics of horizontal and vertical axis offshore floating wind turbines, Philos. Trans. R. Soc. A Math. Phys. Eng. Sci. 373 (2015) 20140076-20140076. doi:10.1098/rsta.2014.0076.

[9] M. Borg, M. Collu, F.P.F.P. Brennan, Offshore Floating Vertical Axis Wind Turbines: Advantages, Disadvantages, and Dynamics Modelling State of the Art, in: Mar. Offshore Renew. Energy (MORE 2012), 26 - 27 Sept. 2012, London, UK, 2012.

[10] J.O. Dabiri, Potential order-of-magnitude enhancement of wind farm power density via counter-rotating vertical-axis wind turbine arrays, J. Renew. Sustain. Energy. 3 (2011) 43104. doi:10.1063/1.3608170.

[11] M. Kinzel, Q. Mulligan, J.O. Dabiri, Energy exchange in an array of vertical-axis wind turbines, J. Turbul. 13 (2012) N38. doi:10.1080/14685248.2012.712698.

[12] S. Zanforlin, T. Nishino, Fluid dynamic mechanisms of enhanced power generation by closely spaced vertical axis wind turbines, Renew. Energy. 99 (2016) 1213-1226. doi:10.1016/j.renene.2016.08.015.

[13] S. Giorgetti, G. Pellegrini, S. Zanforlin, CFD Investigation on the Aerodynamic Interferences between Medium-solidity Darrieus Vertical Axis Wind Turbines, Energy Procedia. 81 (2015) 227-239. doi:10.1016/j.egypro.2015.12.089.

[14] S. Zanforlin, F. Burchi, N. Bitossi, Hydrodynamic Interactions Between Three Closely-spaced Vertical Axis Tidal Turbines, Energy Procedia. 101 (2016) 520-527. doi:10.1016/j.egypro.2016.11.066.

[15] S. Zanforlin, S. Letizia, Improving the Performance of Wind Turbines in Urban Environment by Integrating the Action of a Diffuser with the Aerodynamics of the Rooftops, Energy Procedia. 82 (2015) 774-781. doi:10.1016/j.egypro.2015.11.810.

[16] S. Letizia, S. Zanforlin, Hybrid CFD-source Terms Modelling of a Diffuser-augmented Vertical Axis Wind Turbine, Energy Procedia. 101 (2016) 1280-1287. doi:10.1016/j.egypro.2016.11.144.

[17] I. Paraschivoiu, Double-multiple streamtube model for studying vertical-axis wind turbines, J. Propuls. Power. 4 (1988) 370 377. doi:10.2514/3.23076.

[18] M.R. Castelli, G. Pavesi, L. Battisti, E. Benini, G. Ardizzon, Modeling Strategy and Numerical Validation for a Darrieus Vertical Axis Micro-Wind Turbine, Int. Mech. Eng. Congr. Expo. (2010). doi:10.1115/IMECE2010-39548.

[19] F. Balduzzi, J. Drofelnik, A. Bianchini, G. Ferrara, L. Ferrari, M.S. Campobasso, Darrieus wind turbine blade unsteady aerodynamics: a three-dimensional Navier-Stokes CFD assessment, Energy. 128 (2017) 550-563. doi:10.1016/j.energy.2017.04.017.

[20] K. Hamada, T. Smith, N. Durrani, N. Qin, R. Howell, Unsteady Flow Simulation and Dynamic Stall Around Vertical Axis Wind Turbine Blades, in: 46th AIAA Aerosp. Sci. Meet. Exhib., American Institute of Aeronautics and Astronautics, Reston, Virigina, 2008. doi:10.2514/6.2008-1319.

[21] P. Marsh, D. Ranmuthugala, I. Penesis, G. Thomas, Three-dimensional numerical simulations of straight-bladed vertical axis tidal turbines investigating power output, torque ripple and mounting forces, Renew. Energy. 83 (2015) 67-77. doi:10.1016/j.renene.2015.04.014.

[22] R. Howell, N. Qin, J. Edwards, N. Durrani, Wind tunnel and numerical study of a small vertical axis wind turbine, Renew. Energy. 35 (2010) 412-422. doi:10.1016/j.renene.2009.07.025.

[23] H.F. Lam, H.Y. Peng, Study of wake characteristics of a vertical axis wind turbine by two- and three-dimensional computational fluid dynamics simulations, Renew. Energy. 90 (2016) 386-398. doi:10.1016/j.renene.2016.01.011.

[24] Q. Li, T. Maeda, Y. Kamada, J. Murata, T. Kawabata, K. Shimizu, T. Ogasawara, A. Nakai, T. Kasuya, Wind tunnel and numerical study of a straight-bladed vertical axis wind turbine in three-dimensional analysis (Part I: For predicting aerodynamic loads and performance), Energy. 106 (2016) 443-452. doi:10.1016/j.energy.2016.03.089. 
[25] R. Gosselin, G. Dumas, M. Boudreau, Parametric study of H-Darrieus vertical-axis turbines using CFD simulations, J. Renew. Sustain. Energy. 8 (2016) 53301. doi:10.1063/1.4963240.

[26] A. Alaimo, A. Esposito, A. Messineo, C. Orlando, D. Tumino, 3D CFD Analysis of a Vertical Axis Wind Turbine, Energies. 8 (2015) 3013-3033. doi:10.3390/en8043013.

[27] C. Bak, Sensitivity of Key Parameters in Aerodynamic Wind Turbine Rotor Design on Power and Energy Performance, J. Phys. Conf. Ser. 75 (2007) 12008. doi:10.1088/1742-6596/75/1/012008.

[28] A. Mason-Jones, D.M. O’Doherty, C.E. Morris, T. O’Doherty, C.B. Byrne, P.W. Prickett, R.I. Grosvenor, I. Owen, S. Tedds, R.J. Poole, Non-dimensional scaling of tidal stream turbines, Energy. 44 (2012) 820-829. doi:10.1016/j.energy.2012.05.010.

[29] R.E. Sheldahl, P.C. Klimas, Aerodynamic characteristics of seven symmetrical airfoil sections through 180-degree angle of attack for use in aerodynamic analysis of vertical axis wind turbines, 1981. doi:10.2172/6548367.

[30] S. Brusca, R. Lanzafame, M. Messina, Design of a vertical-axis wind turbine: how the aspect ratio affects the turbine?s performance, Int. J. Energy Environ. Eng. 5 (2014) 333-340. doi:10.1007/s40095-014-0129-x.

[31] C.E. Soraghan, P. Jamieson, P.W.E. Leithead, Influence of Lift to Drag Ratio on Optimal Aerodynamic Performance of Straight Blade Vertical Axis Wind Turbines, in: EWEA Annu. Wind Energy Event, 2013.

[32] S.-C. Roh, S.-H. Kang, Effects of a blade profile, the Reynolds number, and the solidity on the performance of a straight bladed vertical axis wind turbine, J. Mech. Sci. Technol. 27 (2013) 3299-3307. doi:10.1007/s12206-013-0852-x.

[33] W.Z. Shen, R. Mikkelsen, J.N. S?rensen, C. Bak, Tip loss corrections for wind turbine computations, Wind Energy. 8 (2005) 457-475. doi:10.1002/we.153.

[34] T. Burton, N. Jenkins, D. Sharpe, E. Bossanyi, Wind Energy Handbook, 2nd Edition, 2011.

[35] M. Raciti Castelli, A. Dal Monte, M. Quaresimin, E. Benini, Numerical evaluation of aerodynamic and inertial contributions to Darrieus wind turbine blade deformation, Renew. Energy. 51 (2013) 101-112. doi:10.1016/j.renene.2012.07.025.

[36] C. Li, S. Zhu, Y. Xu, Y. Xiao, 2.5D large eddy simulation of vertical axis wind turbine in consideration of high angle of attack flow, Renew. Energy. 51 (2013) 317-330. doi:10.1016/j.renene.2012.09.011.

[37] F.R. Menter, Two-equation eddy-viscosity turbulence models for engineering applications, AIAA J. 32 (1994) 1598-1605. doi: $10.2514 / 3.12149$.

[38] F. R. Menter, Zonal two equation k-U turbulence models for aerodynamic flows. AIAA Paper July 1993;93-2906. 24th Fluid Dynamics Conference.

[39] D. C. Wilcox, Formulation of the k-U turbulence model revisited. AIAA Journal 2008;46(11):2823-38.

[40] Fluent Inc., Fluent User's Manual, pp. 52, 54, 59, 71, 143.

[41] F. Balduzzi, A. Bianchini, R. Maleci, G. Ferrara, L. Ferrari, Critical issues in the CFD simulation of Darrieus wind turbines, Renew. Energy. 85 (2016) 419-435. doi:10.1016/j.renene.2015.06.048.

[42] P.-L. Delafin, T. Nishino, A. Kolios, L. Wang, Comparison of low-order aerodynamic models and RANS CFD for full scale 3D vertical axis wind turbines, Renew. Energy. 109 (2017) 564-575. doi:10.1016/j.renene.2017.03.065.

[43] M. Elkhoury, T. Kiwata, E. Aoun, Experimental and numerical investigation of a three-dimensional vertical-axis wind turbine with variable-pitch, J. Wind Eng. Ind. Aerodyn. 139 (2015) 111-123. doi:10.1016/j.jweia.2015.01.004.

[44] T. Maître, E. Amet, C. Pellone, Modeling of the flow in a Darrieus water turbine: Wall grid refinement analysis and comparison with experiments, Renew. Energy. 51 (2013) 497-512. doi:10.1016/j.renene.2012.09.030.

[45] C.J.S. Ferreira, H. Bijl, G. van Bussel, G. van Kuik, Simulating Dynamic Stall in a 2D VAWT: Modeling strategy, verification and validation with Particle Image Velocimetry data, J. Phys. Conf. Ser. 75 (2007) 12023. doi:10.1088/1742-6596/75/1/012023.

[46] A. Rezaeiha, I. Kalkman, B. Blocken, CFD simulation of a vertical axis wind turbine operating at a moderate tip speed ratio: Guidelines for minimum domain size and azimuthal increment, Renew. Energy. 107 (2017) 373-385. doi:10.1016/j.renene.2017.02.006.

[47] I.H. Abbott, A.E. Von Doenhoff, Theory of Wing Sections: Including a Summary of Airfoil data, 1959.

[48] C. Simao Ferreira, K. Dixon, C. Hofemann, G. van Kuik, G. van Bussel, VAWT in Skew: Stereo-PIV and Vortex Modeling, in: 47th AIAA Aerosp. Sci. Meet. Incl. New Horizons Forum Aerosp. Expo., American Institute of Aeronautics and Astronautics, Reston, Virigina, 2009. doi:10.2514/6.2009-1219.

[49] S. Armstrong, A. Fiedler, S. Tullis, Flow separation on a high Reynolds number, high solidity vertical axis wind turbine with straight and canted blades and canted blades with fences, Renew. Energy. 41 (2012) 13-22. doi:10.1016/j.renene.2011.09.002.

[50] Y. Li, S.M. Calisal, Three-dimensional effects and arm effects on modeling a vertical axis tidal current turbine, Renew. Energy. 35 (2010) 2325-2334. doi:10.1016/j.renene.2010.03.002. 


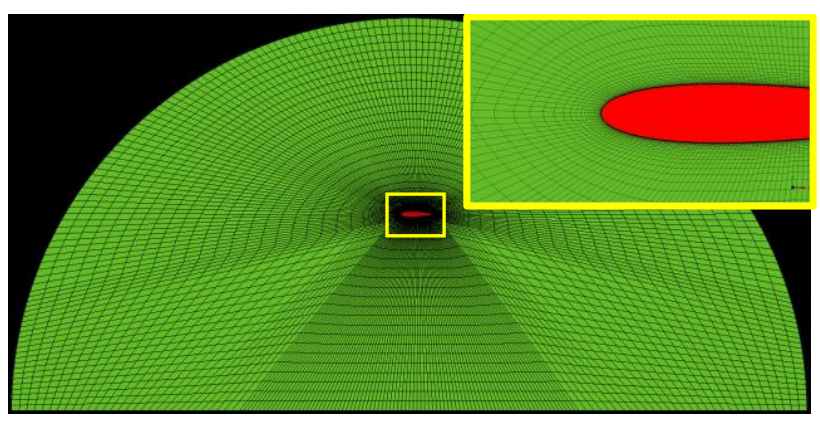

(a)

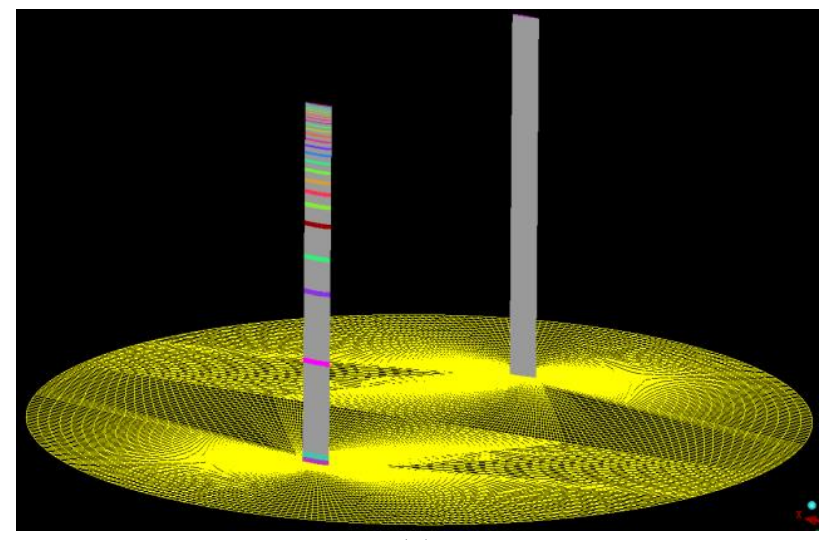

(c)

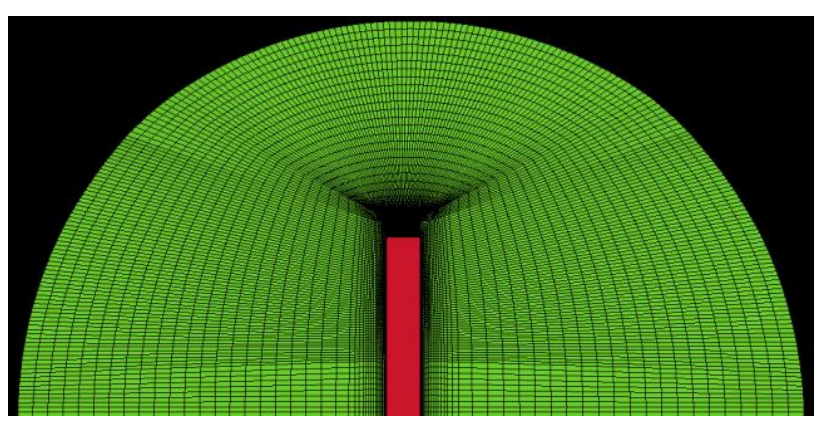

(b)

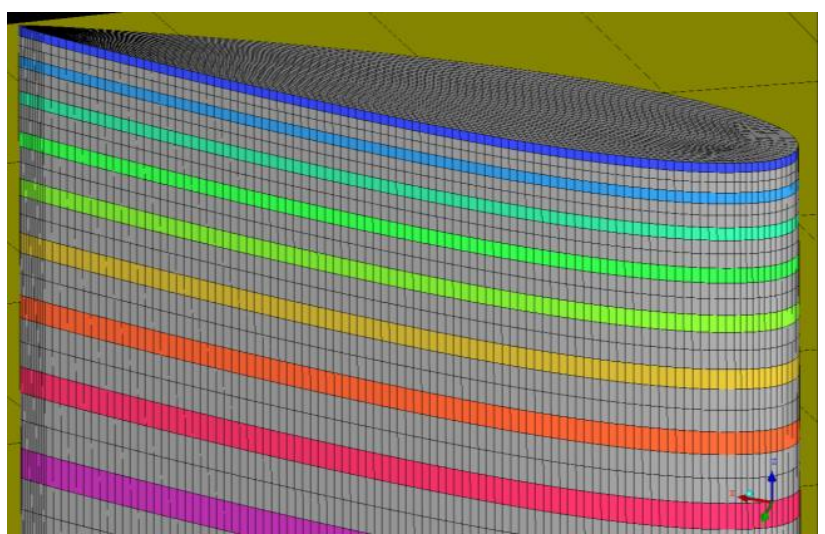

(d)

Figure 1. Details of the rotating grid (half domain; $A R=1.9$ ): (a) cell distribution on a plane normal to the turbine axis (blade is colored in red); (b) cell distribution on a vertical plane cutting the blade; (c) coloured ribbons on the blade in foreground indicate the positions along the semispan where local $\mathrm{C}_{\mathrm{P}}$ is monitored during a simulation; (d) blade tip. 


\section{Flow}
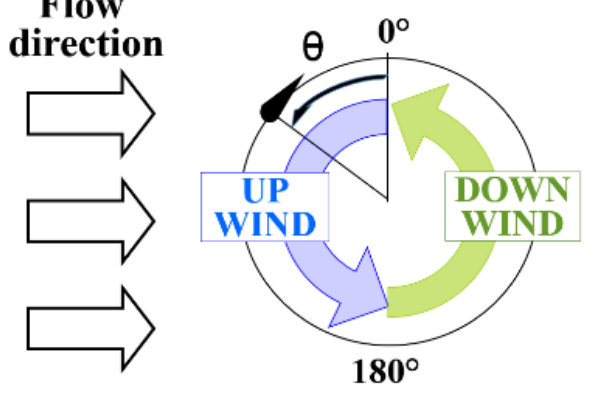

(a)

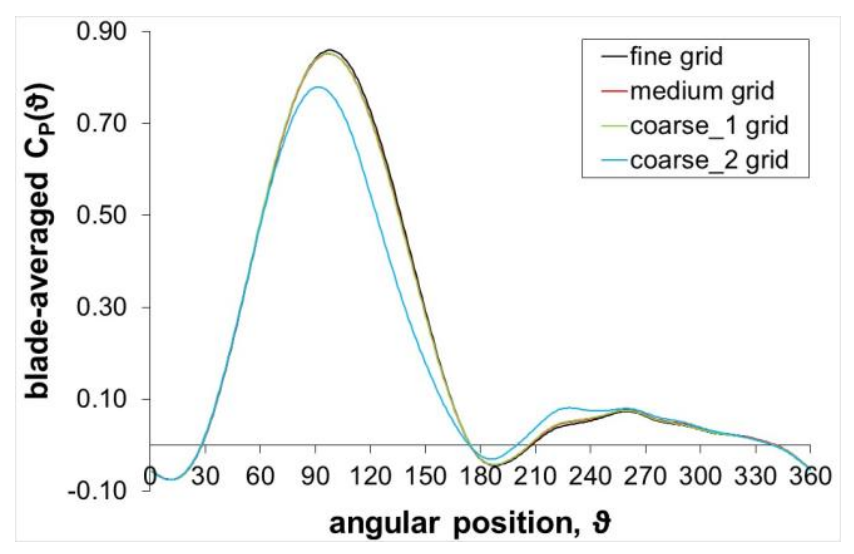

(b)

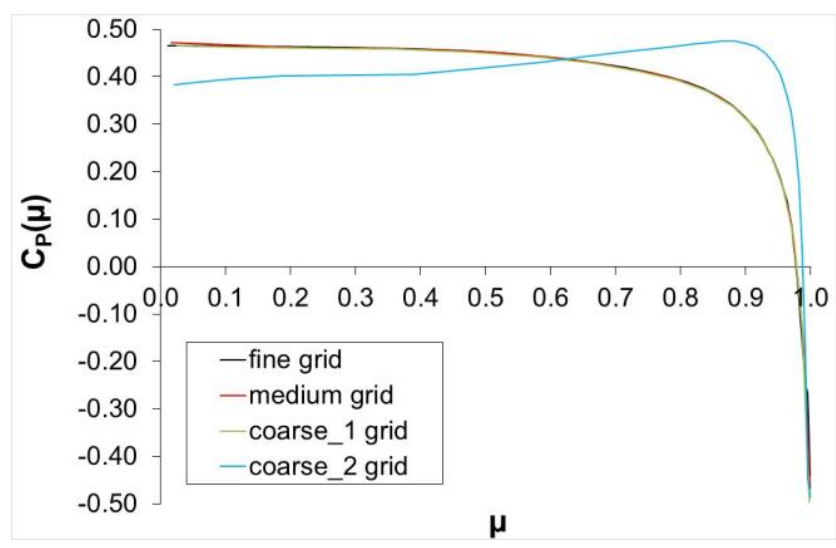

(c)

612 Figure 2. Sensitivity of results to the grid density: (a) schematic representation of the upwind and downwind paths of the blade in one revolution; (b) one-blade $C_{P}(\vartheta)$ averaged on the last revolution; (c) local $C_{P}(\mu)$ calculated adding the contributions of both blades. 


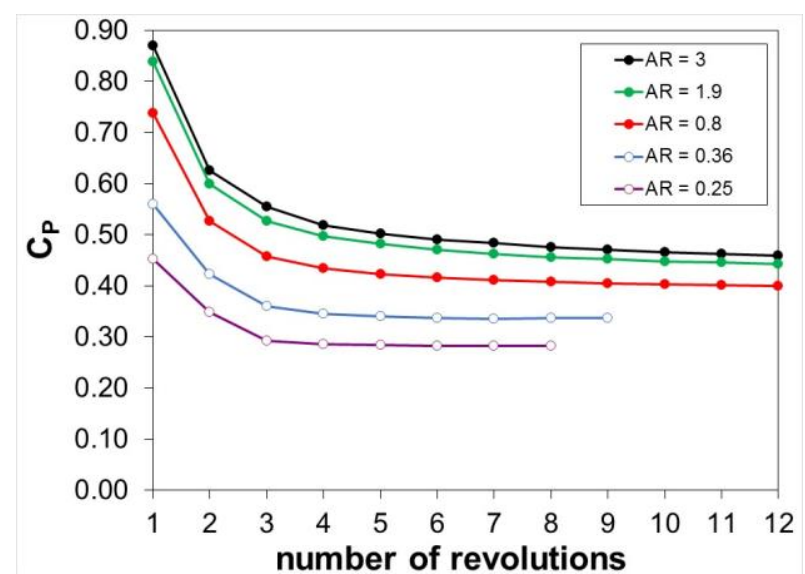

(a)

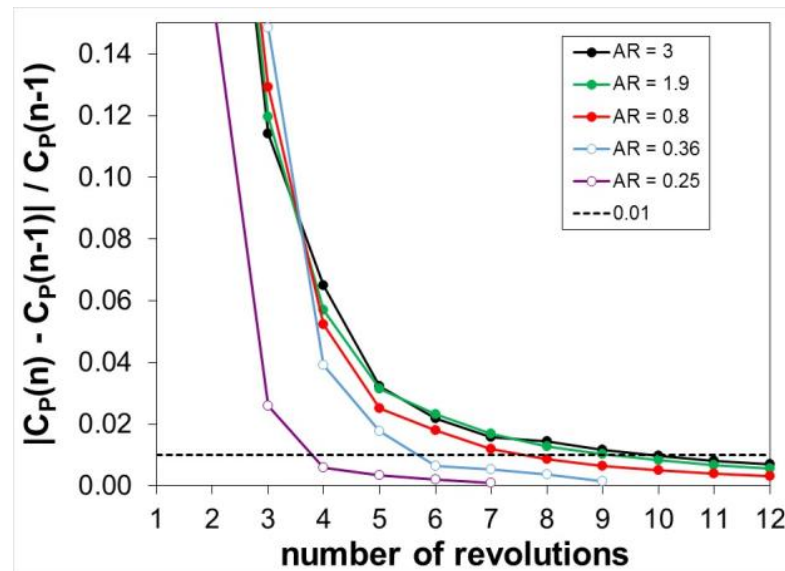

(b)

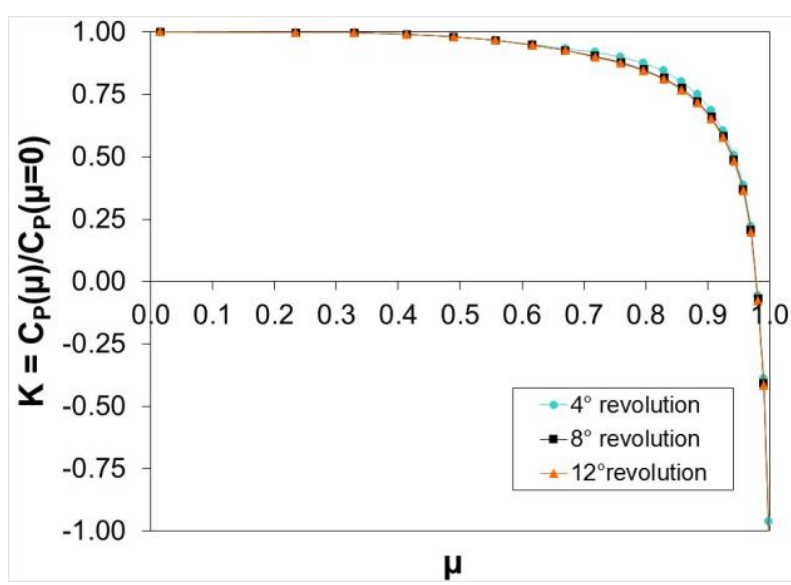

(c)

616

Figure 3. Analysis of the solution temporal convergence: (a) $C_{P}$ vs number of revolutions; (b) normalized temporal variation of $C_{P}$; (c) normalized local $C_{P}$ distribution along the semispan for $A R=0.8$.

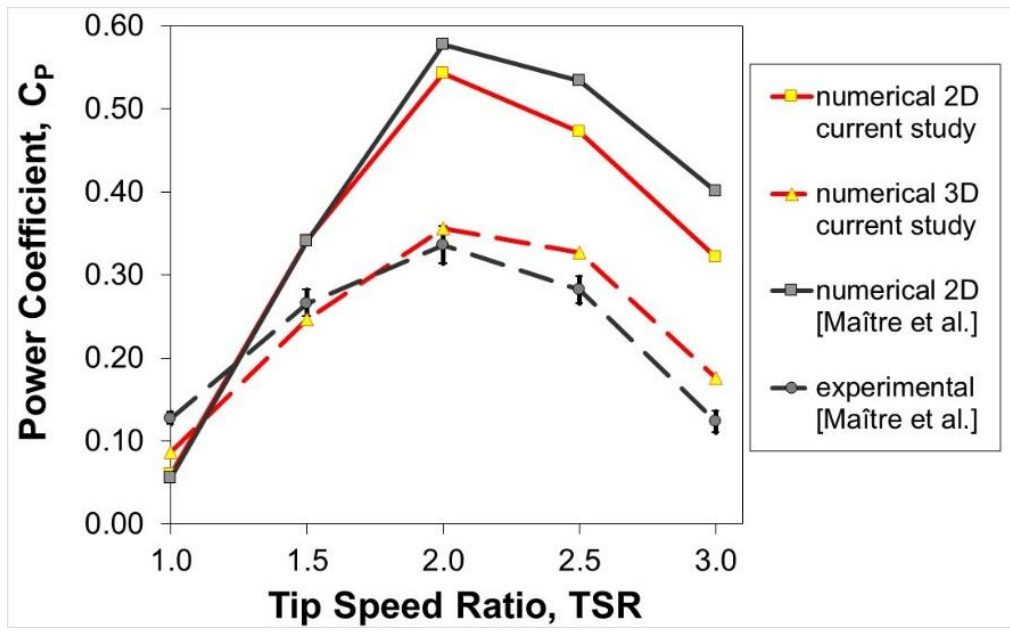

Figure 4. Numerical vs experimental results for the water turbine of Ref. [44]. 


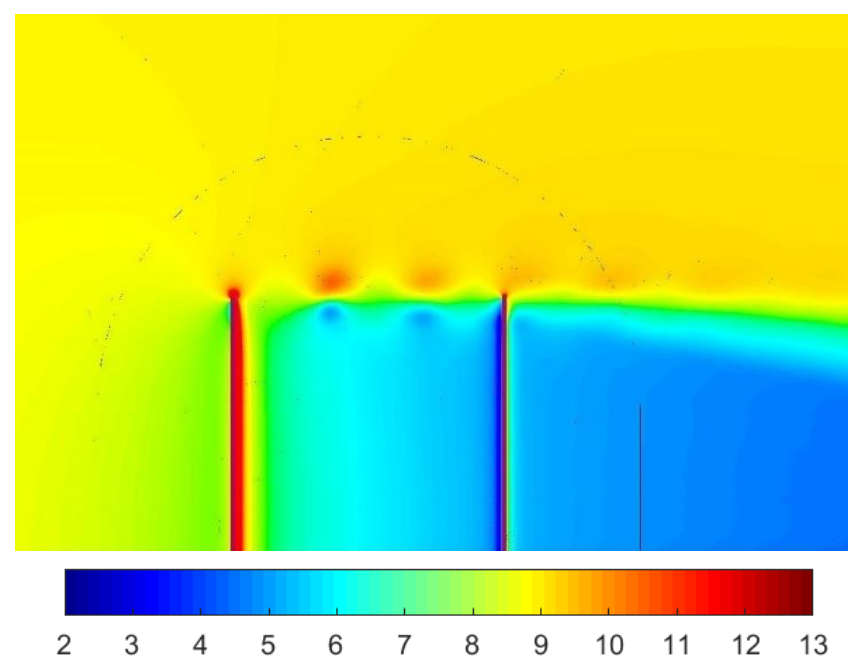

(a)

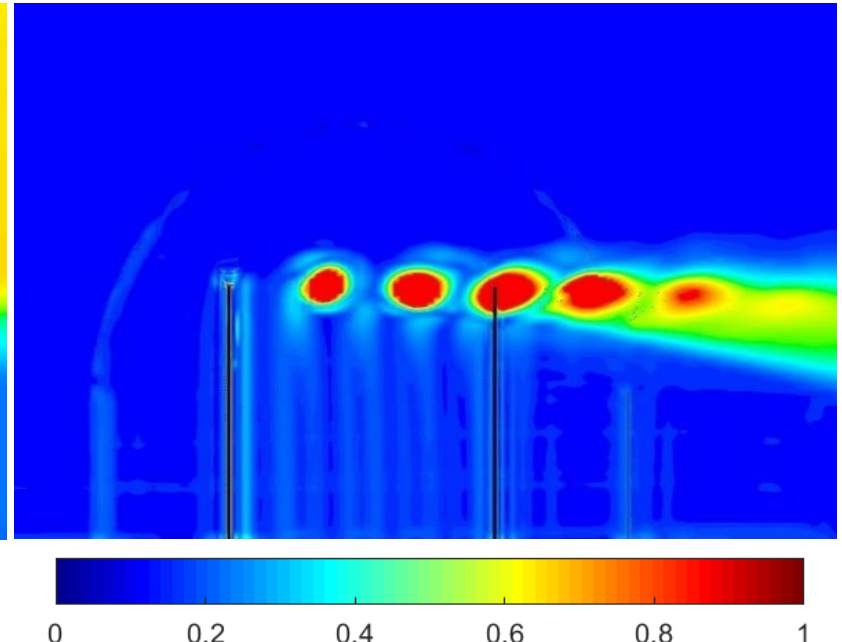

(b)

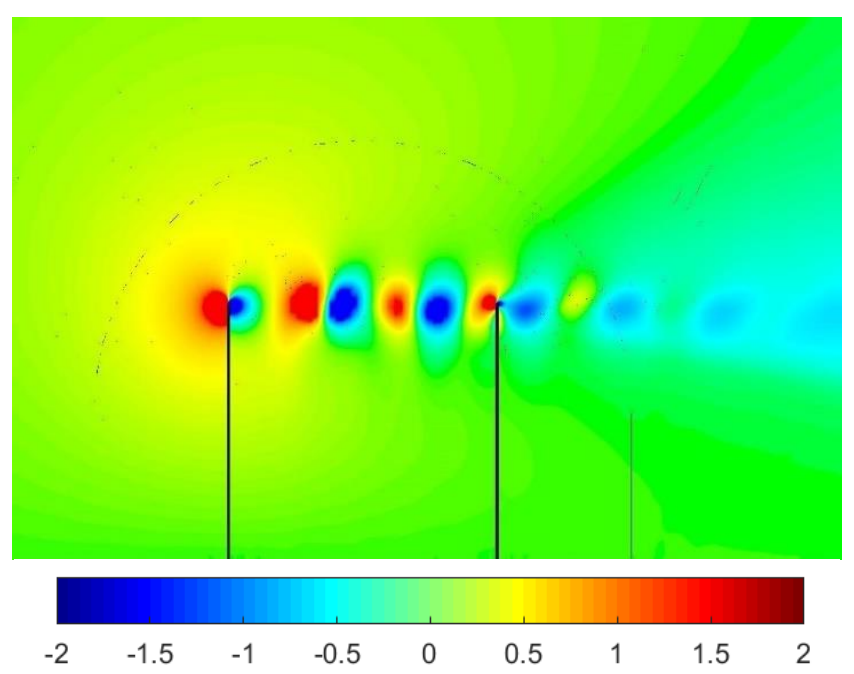

(c)

621 Figure 5. Flow field on the XZ mid-plane for $A R=1.9$ and blade angular position $\vartheta=90^{\circ}$ (wind is blowing from left; blade on the left is

622 at halfway of upwind route, blade on the right is at halfway of the downwind route): (a) velocity magnitude [m/s]; (b) vorticity 623 magnitude [1/s]; (c) vertical velocity $[\mathrm{m} / \mathrm{s}]$. 


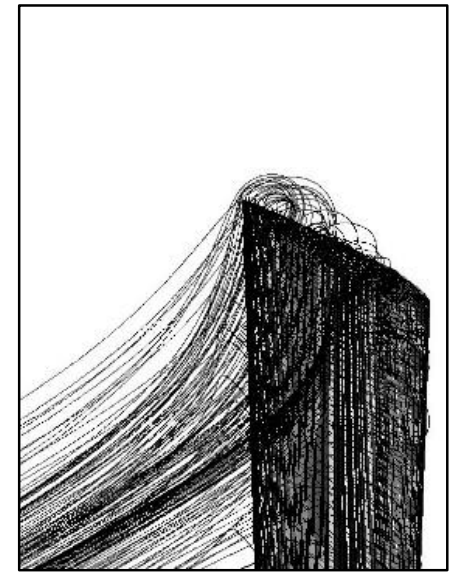

(a)

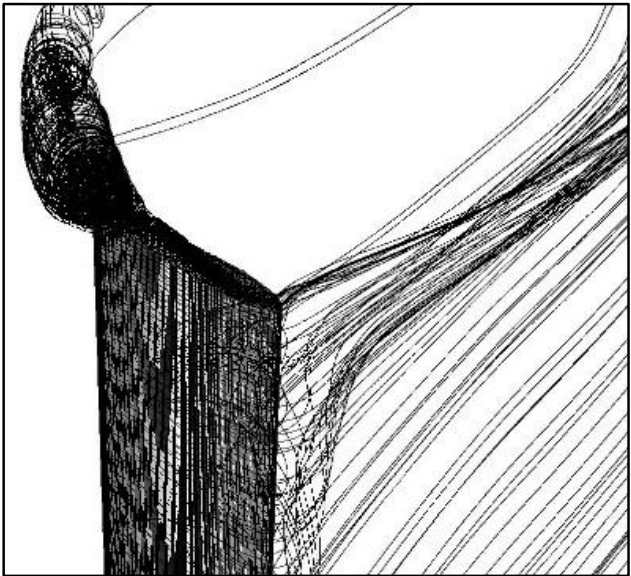

(b)

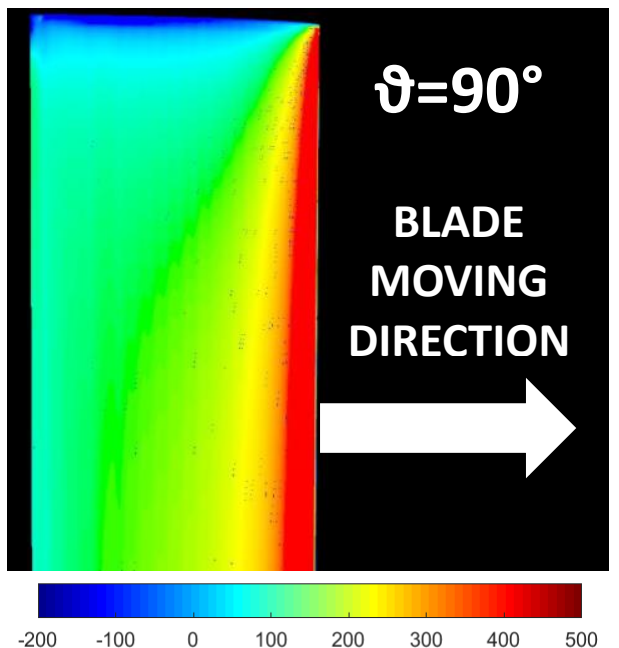

(c)

625 626

Figure 6. Flow features and static pressure for $A R=1.9$ and $\vartheta=90^{\circ}$ : (a) path-lines arriving on the blade tip; (b) path-lines leaving the blade tip; (c) static pressure on the pressure-side of the blade [Pa]. 


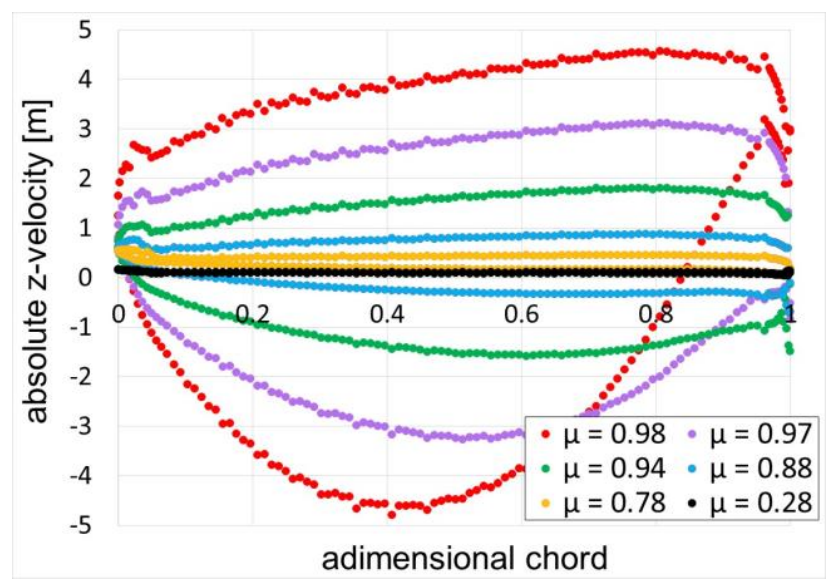

(a)

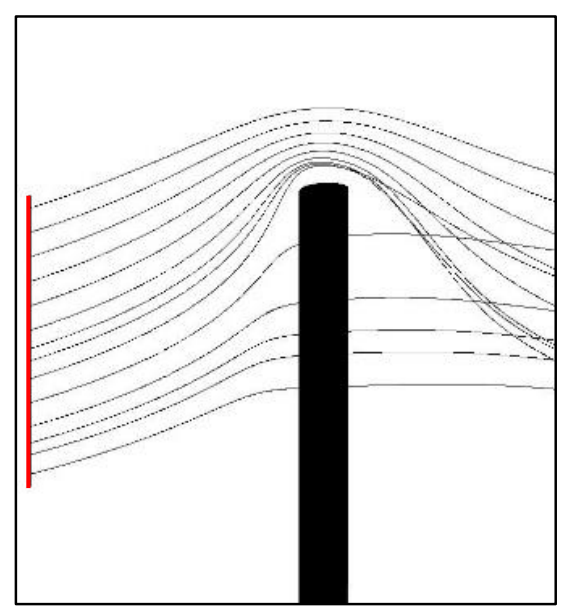

(c)

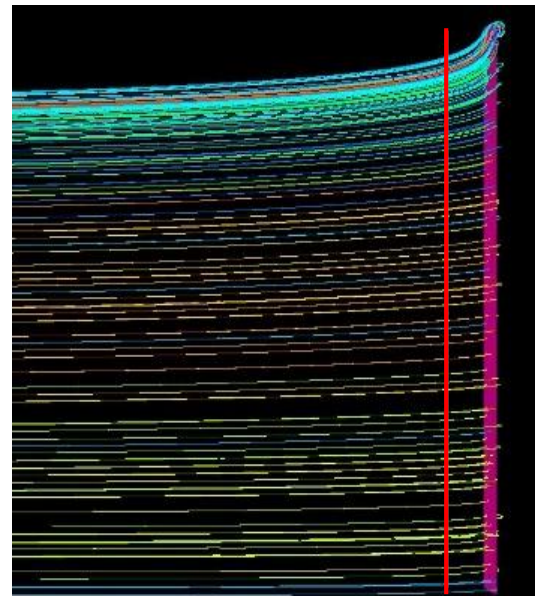

(b)

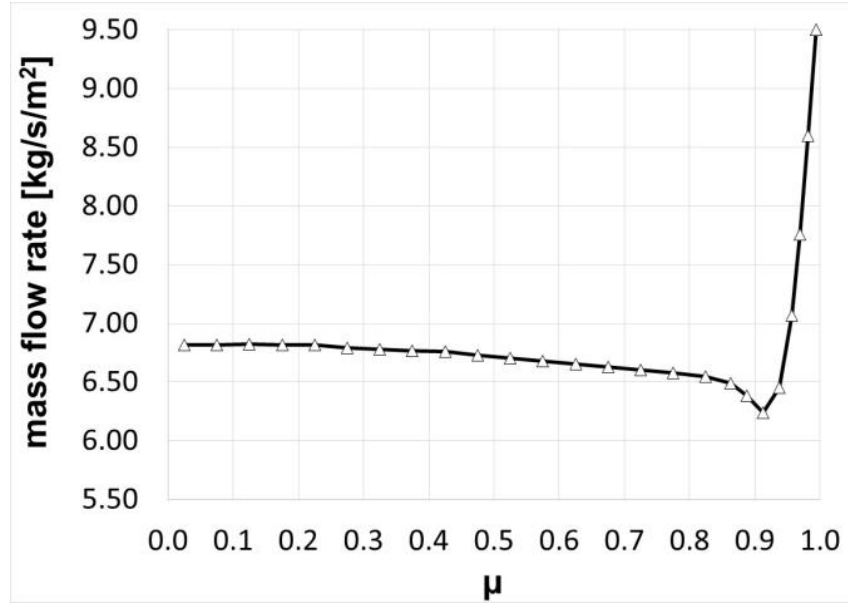

(d)

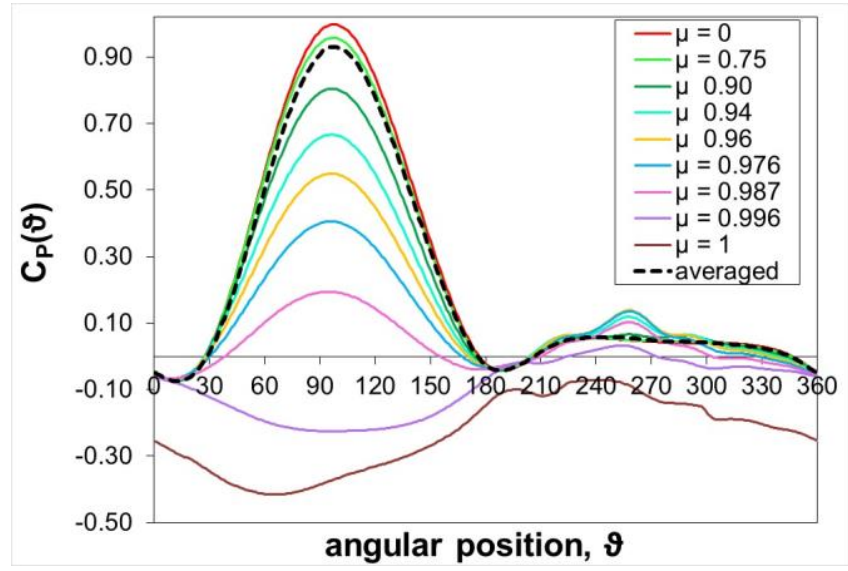

(a)

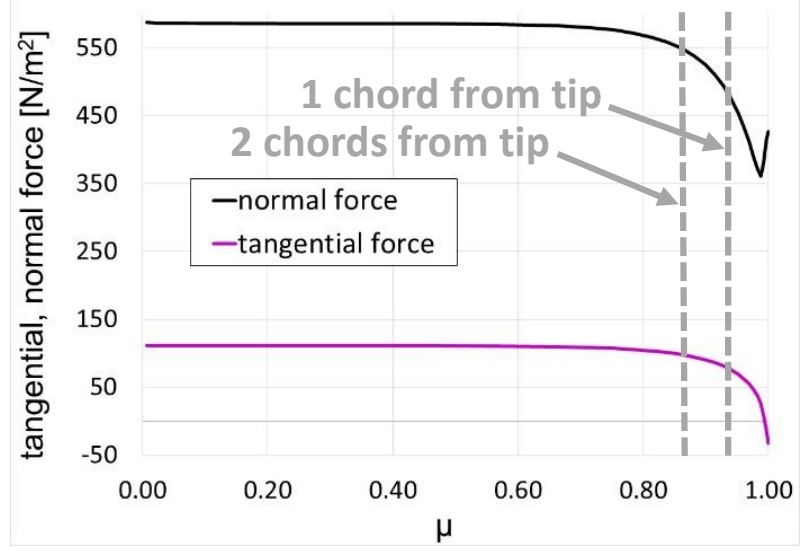

(b)

Figure 7. (a) Z-velocity on blade surface for $A R=1.9$ and $\vartheta=90^{\circ}$; (b) path-lines arriving on the blade (superimposed red line has the same blade length the and is located $1 c$ before the blade) for $A R=1.9$ and $\vartheta=90^{\circ}$; (c) path-lines departing from a line (in red) $1 c$ tall and set $1 \mathrm{c}$ before the blade for $A R=1.9$ and $\vartheta=90^{\circ}$; (d) flow rate across turbine calculated on XZ mid-plane for $A R=1.9$ (blades at $\vartheta=0^{\circ}$, $\left.180^{\circ}\right)$.

Figure 8. Blade performance calculated for $A R=1.9$ and $\vartheta=90^{\circ}$ : (a) instantaneous one-blade power coefficient at different positions $(\mu$ ) 


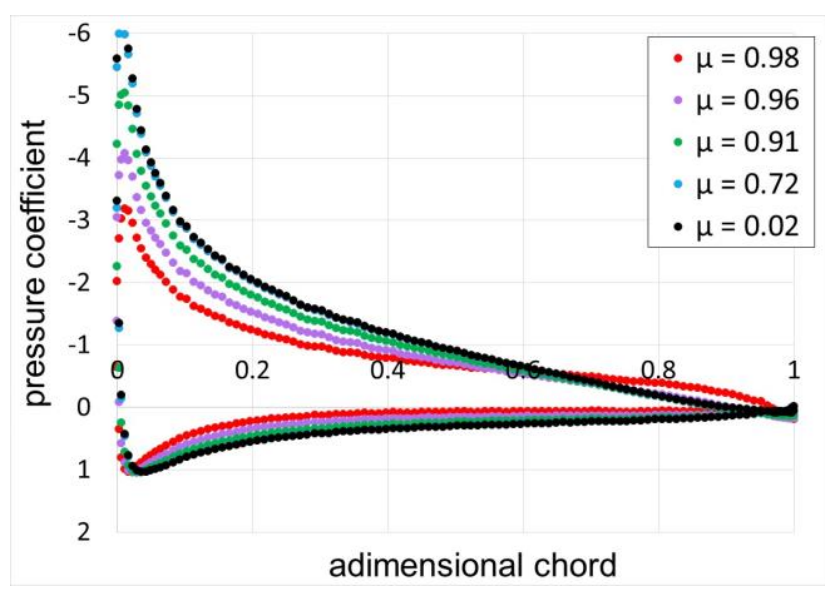

(a)

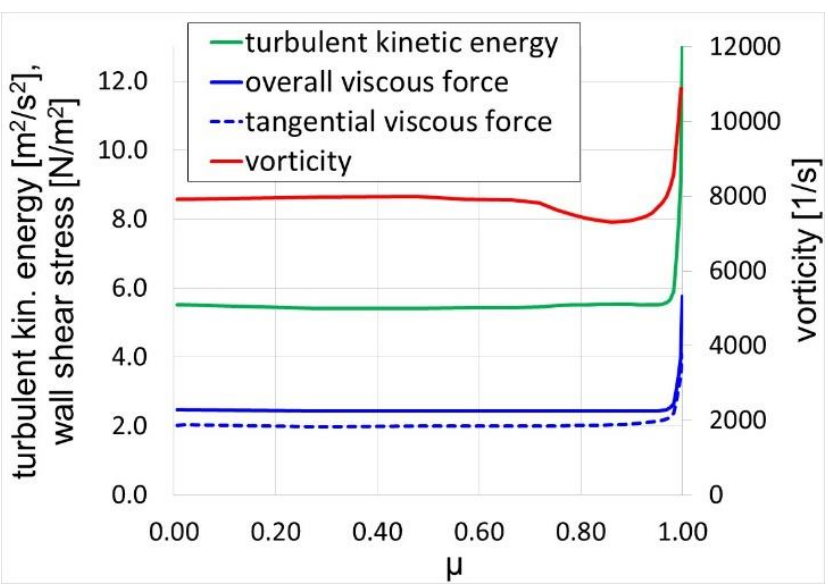

(b)

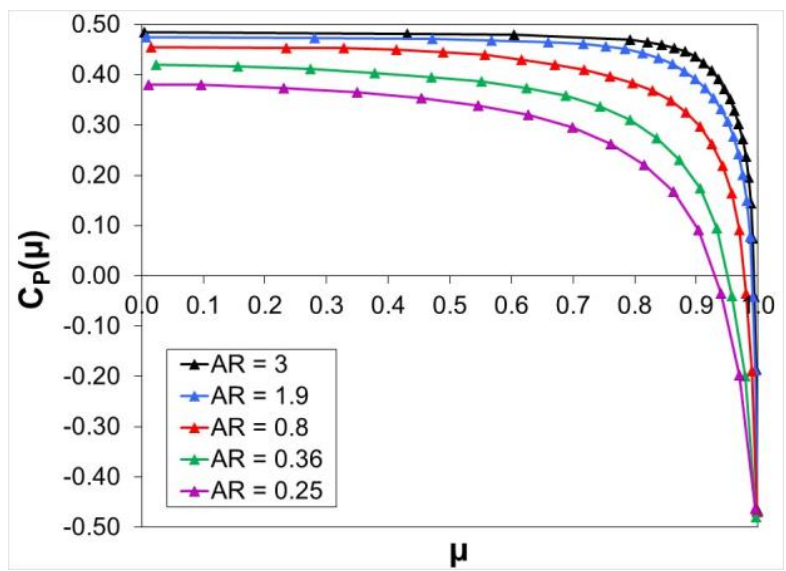

(a)

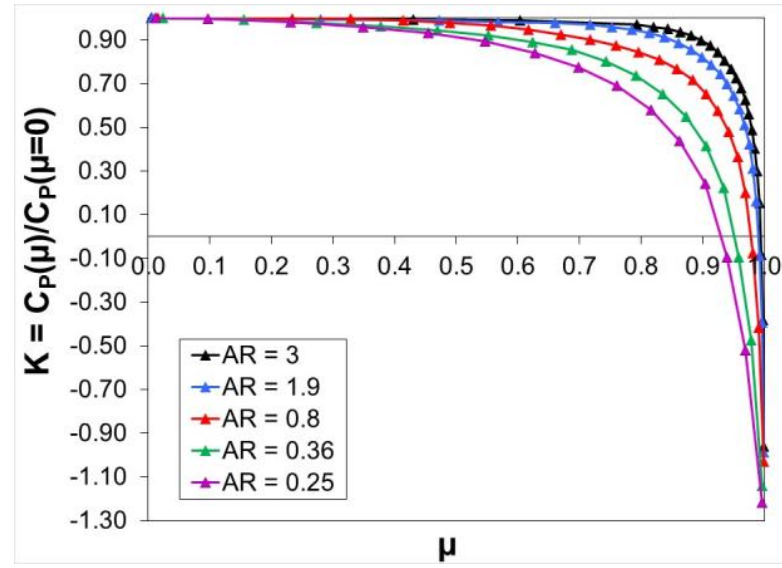

(b)

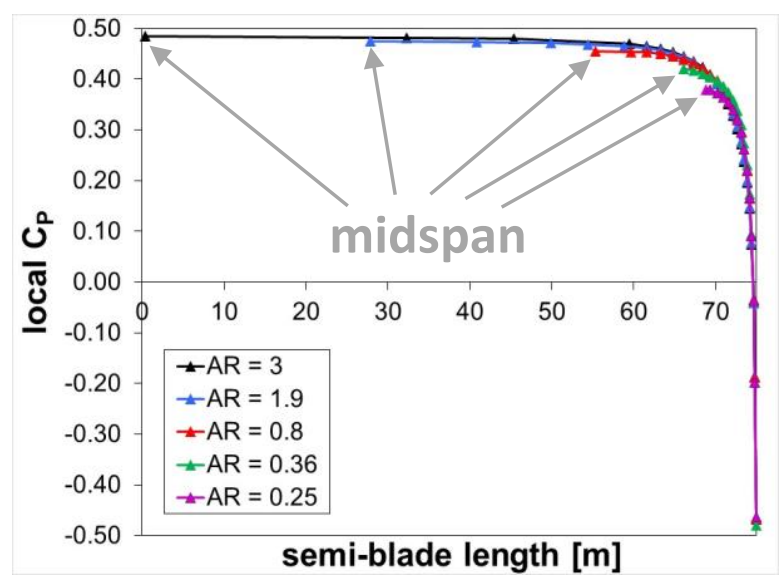

(c)

Figure 10. Blade local performance at different AR: (a) $C_{P}$ distributions along the adimensional semispan; (b) $\mathrm{K}$ distribution along the adimensional semispan; (c) $\mathrm{C}_{\mathrm{P}}$ distributions along the semispan (for all $\mathrm{AR}$, the abscissa at the blade tip is $75 \mathrm{~m}$ ). 


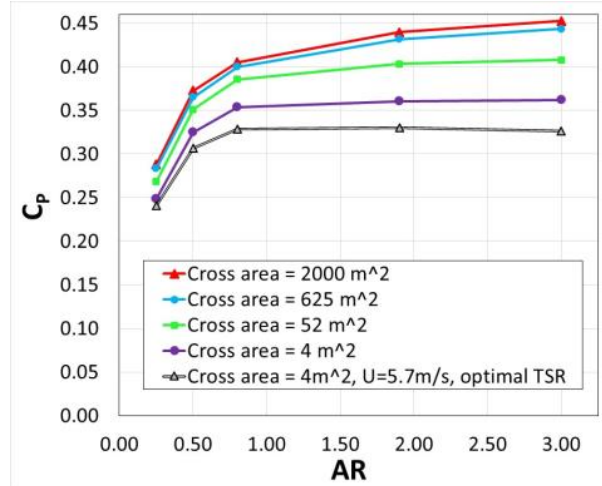

(a)

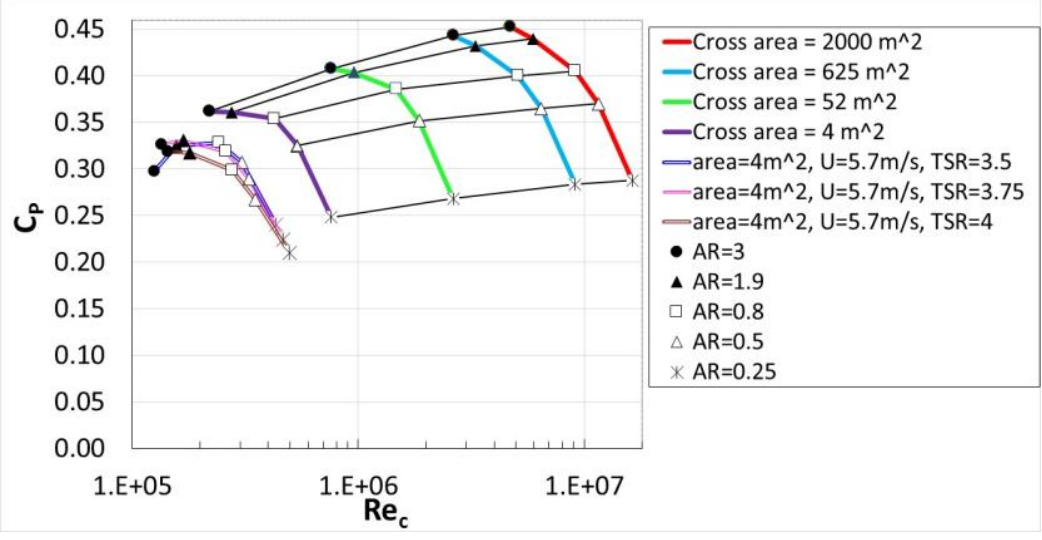

(b)

641 Figure 11. Overall aerodynamic performance of the turbine: (a) $C_{P}$ vs $A R$ for different turbine cross-sectional areas; (b) $C_{P}$ vs $R e_{c}$ for 642 different turbine cross sectional areas, and different $A R$. 


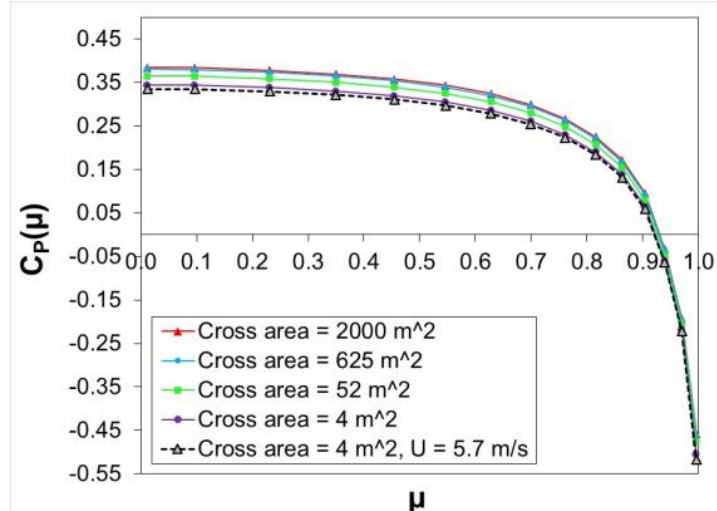

(a)

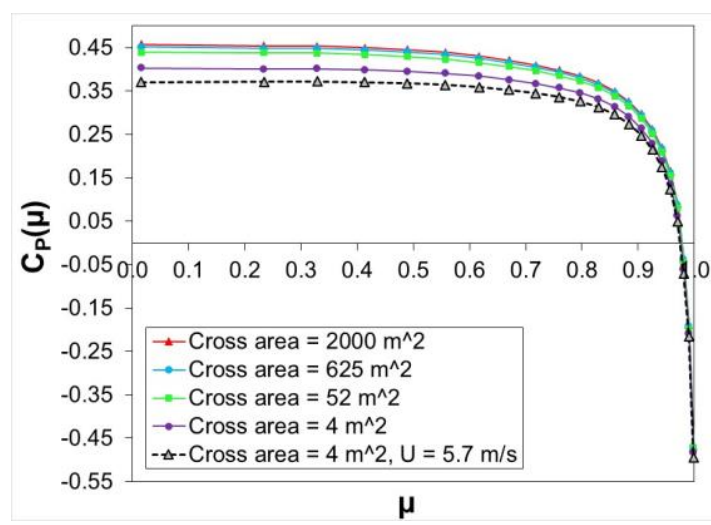

(c)

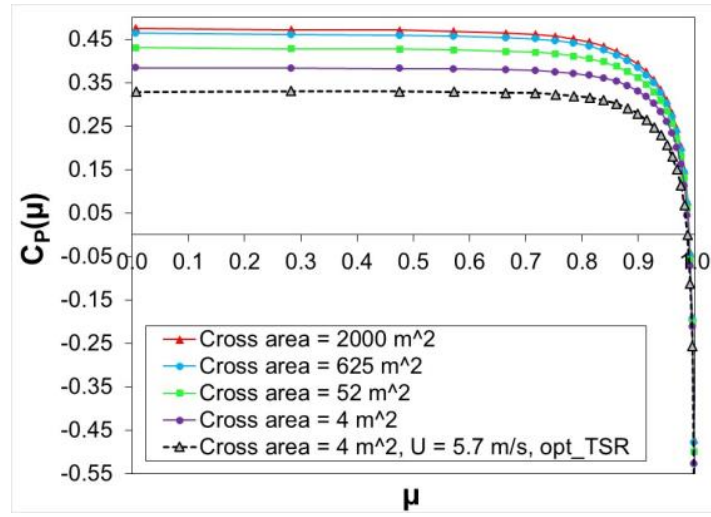

(e)

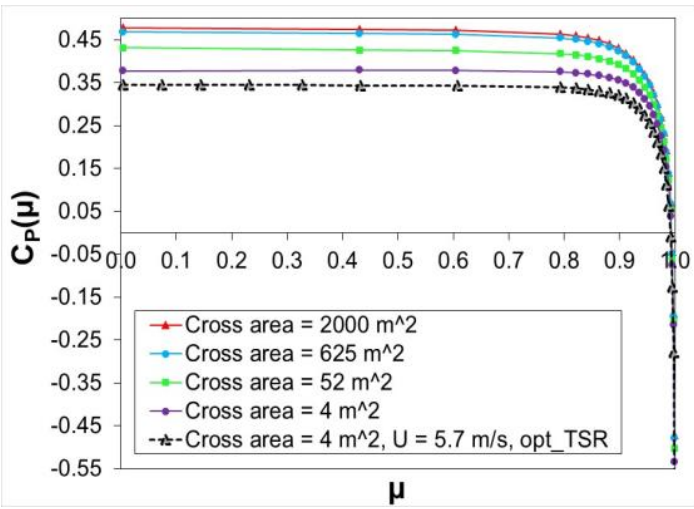

(g)

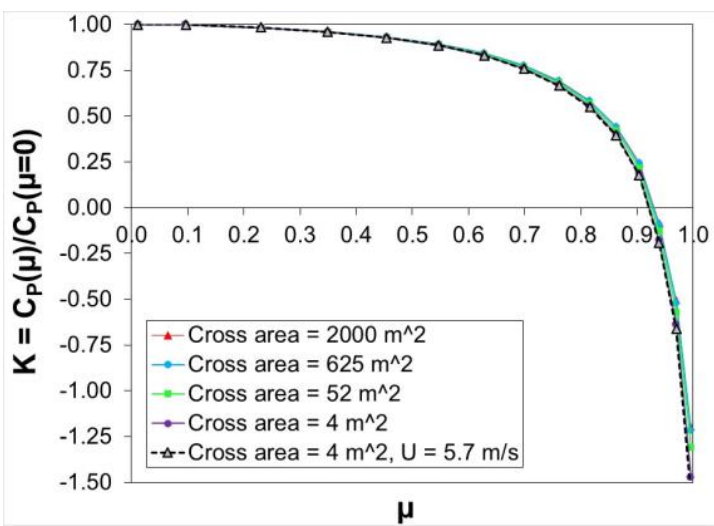

(b)

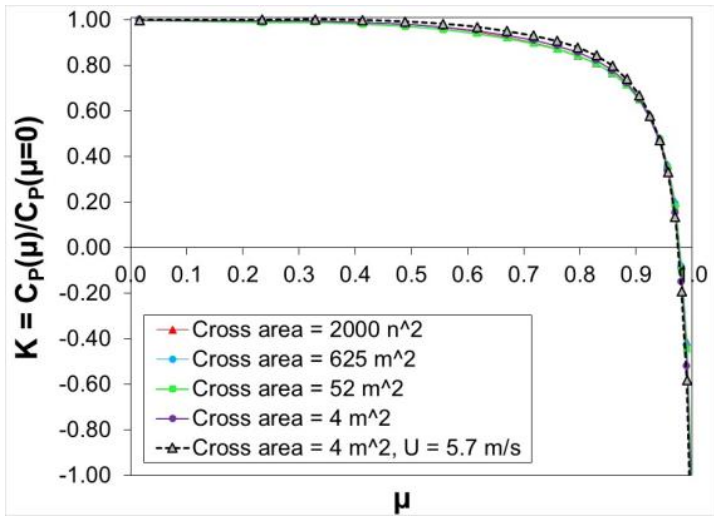

(d)

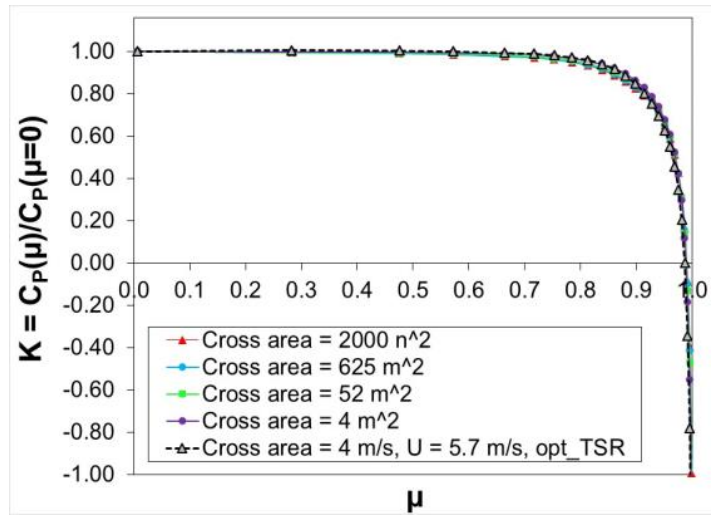

(f)

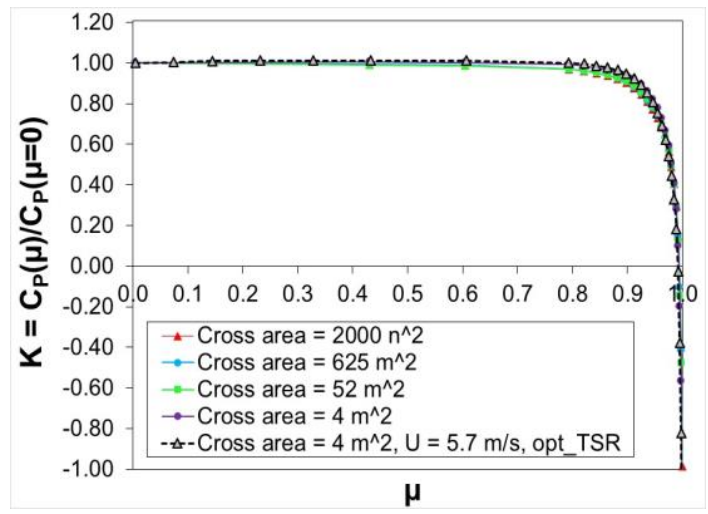

(h)

Figure 12. $C_{P}$ and normalized local $C_{P}$ distributions along the semispan for different turbine cross-areas: (a) $C_{P}$ for $A R=0.25$; (b) $K$ for $A R=0.25$; (c) $C_{P}$ for $A R=0.8$; (d) $K$ for $A R=0.8$; (e) $C_{P}$ for $A R=1.9$; (f) $K$ for $A R=1.9$; (g) $C_{P}$ for $A R=3$; (h) $K$ for $A R=3$. 


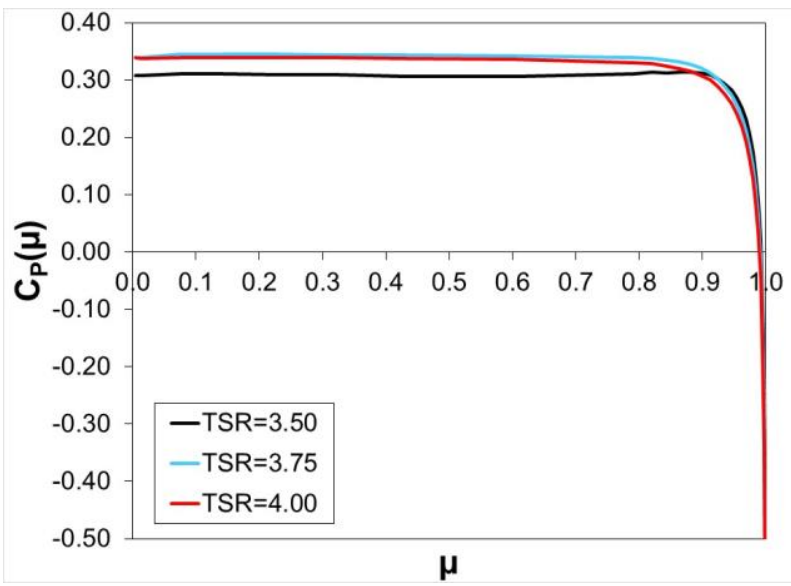

Figure 13. Local $C_{P}$ distribution distributions along the semispan for $A R=3$.

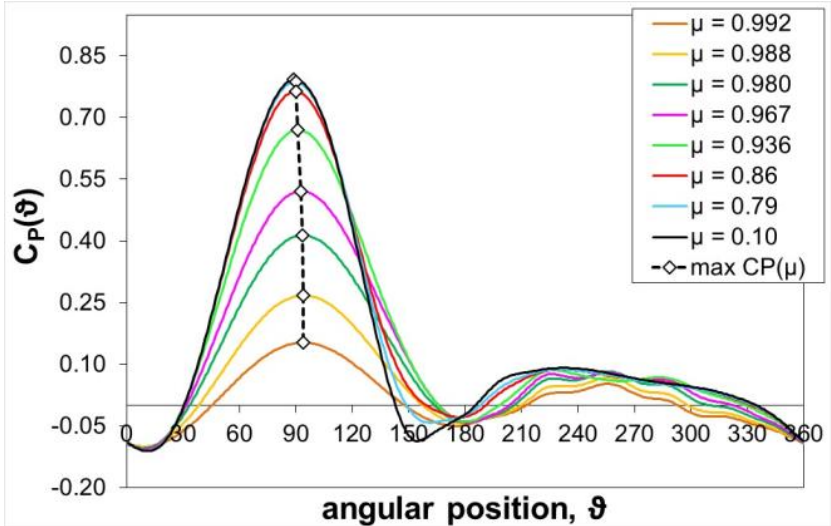

(a)

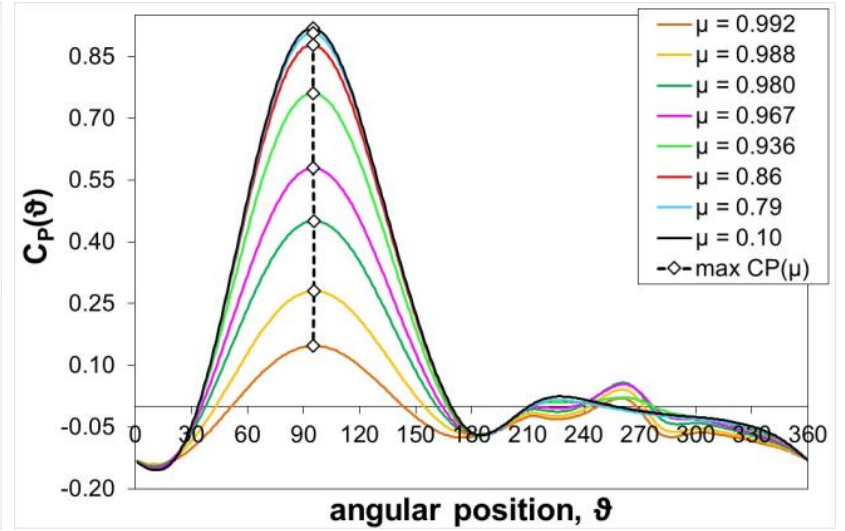

(b)

649 Figure 14. Instantaneous one-blade at different position along the blade semispan, $C_{P}(\mu$ ), for $\mathrm{AR}=3$ : (a) $T S R=3.5$; (b) $T S R=4$.

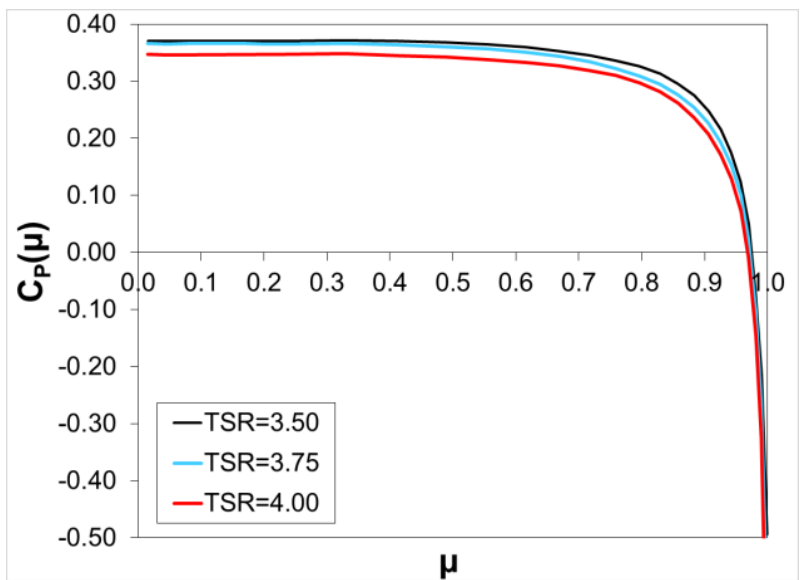

Figure 15. Local $C_{P}$ distribution distributions along the semispan for $A R=0.8$. 


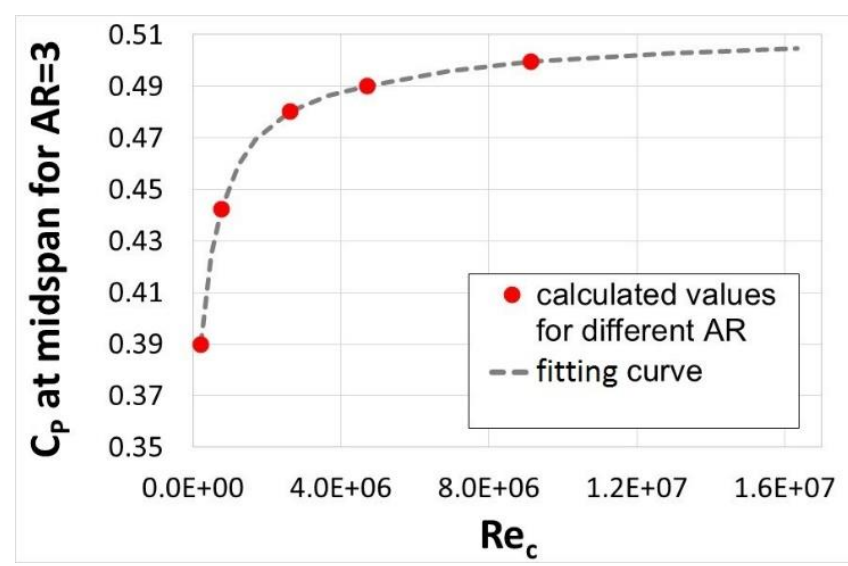

(a)

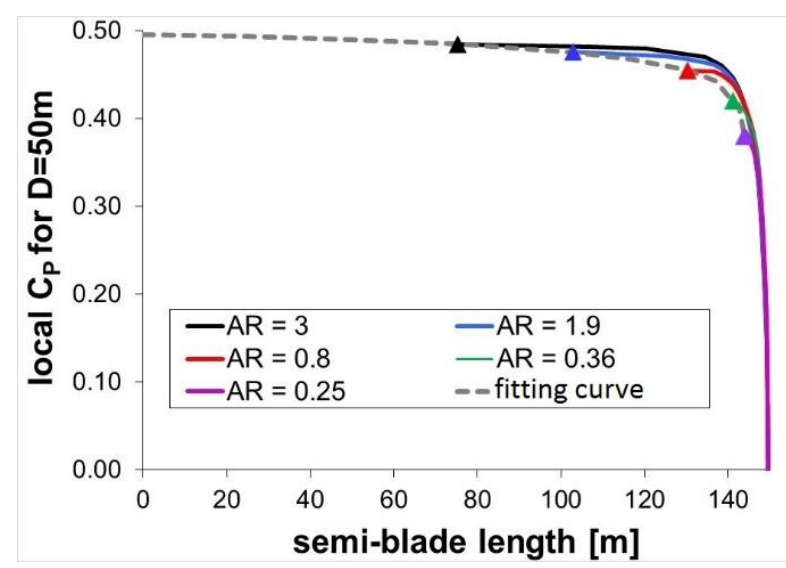

(b)

Figure 16. (a) Fitting curve of $C_{P}$ at midspan as a function of $R e_{c}$, obtained from values of CFD-3D (red circles) performed at $A R=3$; (b) Fitting curve of $C_{P}$ at midspan as a function of blade length, obtained from values of CFD-3D (coloured triangles) performed at a fixed diameter of $50 \mathrm{~m}$ (cases of paragraph 2.2).

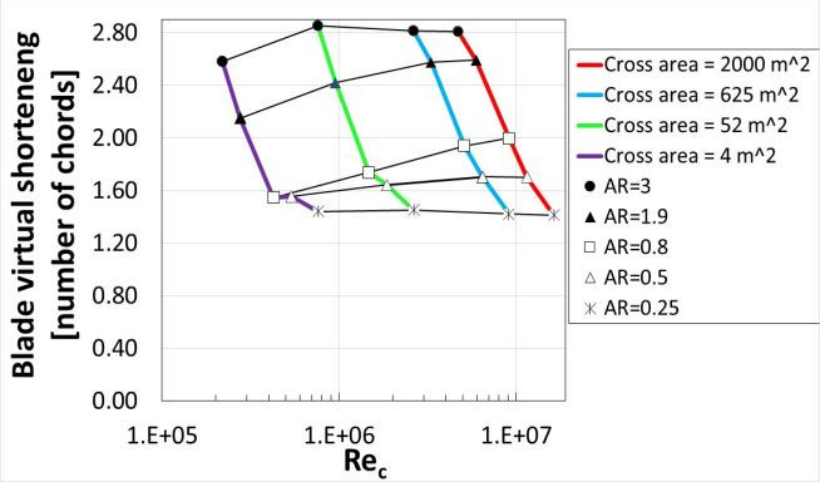

(a)

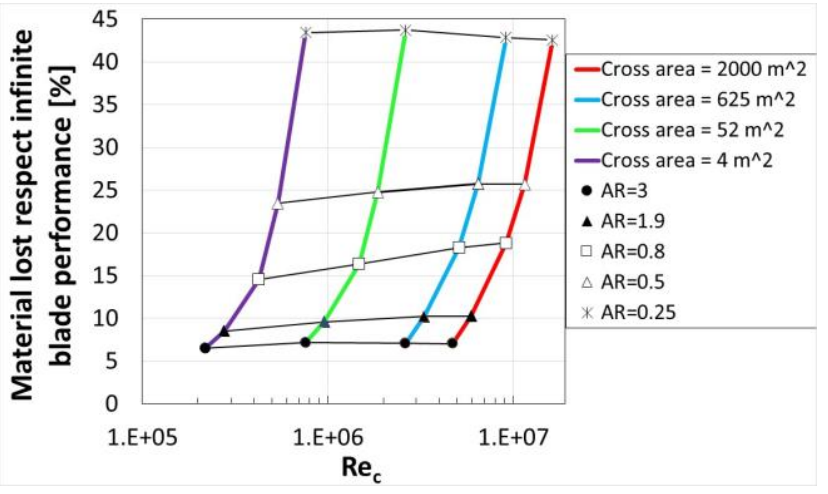

(b)

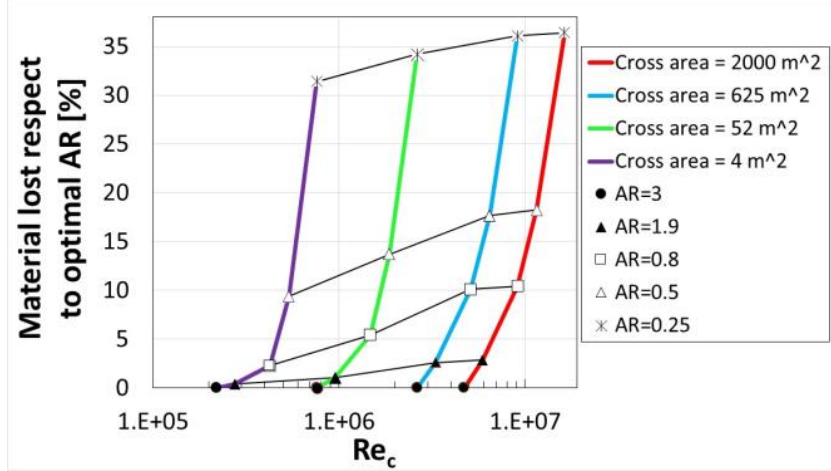

(c)

Figure 17. Tip effects for different turbine sizes and AR for a wind speed of 10m/s: (a) blade virtual shortening, expressed as number of lost chords; (b) percentage of material lost with respect to an infinite-blade turbine; (c) percentage of material lost with respect to the optimal $A R$. 
Tables

Table 1

663 Grid sizes used for grid sensitivity analysis $(\mathrm{AR}=0.8)$.

\begin{tabular}{cccccc}
\hline Grid & $\begin{array}{c}\text { Airfoil perimeter } \\
\text { cell number }\end{array}$ & $\begin{array}{c}\text { Semi-spanwise } \\
\text { cell number }\end{array}$ & $\begin{array}{c}\text { Cell height at the } \\
\text { blade tip [m] }\end{array}$ & $\begin{array}{c}\text { Rotating domain } \\
\text { cell number }\end{array}$ & $\begin{array}{c}\text { Overall domain } \\
\text { cell number }\end{array}$ \\
\hline fine & 308 & 88 & 0.03 & $4.40 \mathrm{M}$ & $5.44 \mathrm{M}$ \\
medium & 220 & 68 & 0.05 & $2.52 \mathrm{M}$ & $3.56 \mathrm{M}$ \\
coarse_1 & 220 & 34 & 0.09 & $1.58 \mathrm{M}$ & $2.18 \mathrm{M}$ \\
coarse_2 & 72 & 57 & 0.06 & $1.47 \mathrm{M}$ & $2.51 \mathrm{M}$ \\
\hline
\end{tabular}

664

Table 2

Grid overall cell number. $\left.{ }^{*}\right)$ the complete domain is considered (i.e., without any symmetry assumption).

\begin{tabular}{ccccccc}
\hline Domain & $\mathrm{AR}=0.25(*)$ & $\mathrm{AR}=0.36(*)$ & $\mathrm{AR}=0.50(*)$ & $\mathrm{AR}=0.80$ & $\mathrm{AR}=1.90$ & $\mathrm{AR}=3.00$ \\
\hline Rotating domain & $3.65 \mathrm{M}$ & $3.94 \mathrm{M}$ & $4.47 \mathrm{M}$ & $2.58 \mathrm{M}$ & $3.69 \mathrm{M}$ & $4.86 \mathrm{M}$ \\
Fixed domain & $1.44 \mathrm{M}$ & $1.50 \mathrm{M}$ & $1.55 \mathrm{M}$ & $1.00 \mathrm{M}$ & $1.46 \mathrm{M}$ & 1.88 \\
\hline
\end{tabular}

Table 3

671

Operating conditions and aerodynamic losses due to blade finite length at fixed turbine diameter of $50 \mathrm{~m}$ and wind speed of $10 \mathrm{~m} / \mathrm{s}$. (§) values of $C_{P}(\mu=0)$ extrapolated at $\mathrm{AR}=6$.

\begin{tabular}{|c|c|c|c|c|c|c|c|c|}
\hline $\begin{array}{l}\text { Cross-sectional } \\
\text { area }\left[\mathbf{m}^{2}\right]\end{array}$ & $\mathbf{A R}$ & $\mathbf{H}[\mathbf{m}]$ & $\mathrm{C}[\mathrm{m}]$ & $\mathbf{A R} \mathbf{R}^{*}=\mathbf{H} / \mathbf{c}$ & $\Omega[\mathrm{rad} / \mathrm{s}]$ & $\boldsymbol{R e}_{c}$ & $\begin{array}{c}\text { Blade virtual } \\
\text { Shortening } \\
\text { [chords number] }\end{array}$ & $\begin{array}{c}\text { Power lost } \\
\left.\left[\% \text { of } 2 D^{\S}\right)\right]\end{array}$ \\
\hline 625 & 0.25 & 12.50 & 3.770 & 3.32 & 1.40 & $9.13 \mathrm{E}+06$ & 1.43 & 42.96 \\
\hline 900 & 0.36 & 18.00 & 3.770 & 4.77 & 1.40 & $9.13 \mathrm{E}+06$ & 1.54 & 32.30 \\
\hline 2000 & 0.80 & 40.00 & 3.770 & 10.61 & 1.40 & $9.13 \mathrm{E}+06$ & 1.95 & 18.39 \\
\hline 4750 & 1.90 & 95.00 & 3.770 & 25.20 & 1.40 & $9.13 \mathrm{E}+06$ & 2.59 & 10.26 \\
\hline 7500 & 3.00 & 150.00 & 3.770 & 39.79 & 1.40 & $9.13 \mathrm{E}+06$ & 2.95 & 7.42 \\
\hline
\end{tabular}


Table 4

675 Operating conditions and aerodynamic losses due to blade finite length for wind speed of $10 \mathrm{~m} / \mathrm{s}$. $(\S)$ values of $C_{P}(\mu=0)$ extrapolated 676 at $A R=6$. ( $\S)$ for a fixed area.

\begin{tabular}{|c|c|c|c|c|c|c|c|c|c|c|}
\hline $\begin{array}{c}\text { Cross- } \\
\text { sectional } \\
\text { area }\left[\mathbf{m}^{2}\right]\end{array}$ & $A R$ & $D[\mathrm{~m}]$ & $H[\mathrm{~m}]$ & $c[\mathbf{m}]$ & $A R^{*}$ & $\Omega[\mathrm{rad} / \mathrm{s}]$ & $R e_{c}$ & $\begin{array}{c}\text { Blade } \\
\text { virtual } \\
\text { shortening } \\
\text { [chord } \\
\text { number] }\end{array}$ & $\begin{array}{l}\text { Power lost } \\
\left.\text { [\% of } 2 D^{\S}\right]\end{array}$ & $\begin{array}{c}\text { Power lost } \\
{[\% \text { of }} \\
\text { optimal } \\
\left.A R^{\S \S}\right]\end{array}$ \\
\hline 4.34 & 0.25 & 4.17 & 1.04 & 0.314 & 3.32 & 16.80 & $7.61 \mathrm{E}+05$ & 1.44 & 43.5 & 31.4 \\
\hline 4.34 & 0.50 & 2.95 & 1.47 & 0.222 & 6.63 & 23.76 & $5.38 \mathrm{E}+05$ & 1.56 & 23.5 & 9.4 \\
\hline 4.34 & 0.80 & 2.33 & 1.86 & 0.176 & 10.61 & 30.05 & $4.25 \mathrm{E}+05$ & 1.55 & 14.6 & 2.3 \\
\hline 4.34 & 1.90 & 1.51 & 2.87 & 0.114 & 25.20 & 46.32 & $2.76 \mathrm{E}+05$ & 2.15 & 8.6 & 0.4 \\
\hline 4.34 & 3.00 & 1.20 & 3.61 & 0.091 & 39.79 & 58.20 & $2.20 \mathrm{E}+05$ & 2.58 & 6.5 & 0.0 \\
\hline 52.1 & 0.25 & 14.44 & 3.61 & 1.088 & 3.32 & 4.85 & $2.64 \mathrm{E}+06$ & 1.45 & 43.7 & 34.2 \\
\hline 52.1 & 0.50 & 10.21 & 5.10 & 0.770 & 6.63 & 6.86 & $1.86 \mathrm{E}+06$ & 1.64 & 24.8 & 13.7 \\
\hline 52.1 & 0.80 & 8.07 & 6.46 & 0.608 & 10.61 & 8.67 & $1.47 \mathrm{E}+06$ & 1.74 & 16.4 & 5.4 \\
\hline 52.1 & 1.90 & 5.24 & 9.95 & 0.395 & 25.20 & 13.37 & $9.56 \mathrm{E}+05$ & 2.42 & 9.6 & 1.1 \\
\hline 52.1 & 3.00 & 4.17 & 12.50 & 0.314 & 39.79 & 16.80 & $7.61 \mathrm{E}+05$ & 2.85 & 7.2 & 0.0 \\
\hline 625 & 0.25 & 50.00 & 12.50 & 3.770 & 3.32 & 1.40 & $9.13 \mathrm{E}+06$ & 1.42 & 42.9 & 36.1 \\
\hline 625 & 0.50 & 35.36 & 17.68 & 2.666 & 6.63 & 1.98 & $6.46 \mathrm{E}+06$ & 1.71 & 25.7 & 17.7 \\
\hline 625 & 0.80 & 27.95 & 22.36 & 2.107 & 10.61 & 2.50 & $5.10 \mathrm{E}+06$ & 1.94 & 18.3 & 9.8 \\
\hline 625 & 1.90 & 18.14 & 34.46 & 1.367 & 25.20 & 3.86 & $3.31 \mathrm{E}+06$ & 2.58 & 10.2 & 2.6 \\
\hline 7.70 & 3.00 & 14.43 & 43.30 & 1.088 & 39.79 & 4.85 & $2.64 \mathrm{E}+06$ & 2.81 & 7.1 & 0.0 \\
\hline 42.96 & 0.25 & 89.44 & 22.36 & 6.744 & 3.32 & 0.78 & $1.63 \mathrm{E}+07$ & 1.41 & 42.6 & 34.6 \\
\hline 26.18 & 0.50 & 63.25 & 31.62 & 4.769 & 6.63 & 1.11 & $1.16 \mathrm{E}+07$ & 1.70 & 25.7 & 18.3 \\
\hline 18.82 & 0.80 & 50.00 & 40.00 & 3.770 & 10.61 & 1.40 & $9.13 \mathrm{E}+06$ & 2.00 & 18.8 & 10.4 \\
\hline 2000 & 1.90 & 32.44 & 61.64 & 2.446 & 25.20 & 2.16 & $5.93 \mathrm{E}+06$ & 2.59 & 10.3 & 2.9 \\
\hline 2000 & 3.00 & 25.82 & 77.46 & 1.947 & 39.79 & 2.71 & $4.72 \mathrm{E}+06$ & 2.81 & 7.1 & 0.0 \\
\hline
\end{tabular}

